\title{
WHO SHOULD PAY FOR TWO-WAY INTERCONNECTION?
}

\author{
Sjaak Hurkens \\ Ángel L. López
}


The Public-Private Sector Research Center is a Research Center based at IESE Business School. Its mission is to develop research that analyses the relationships between the private and public sectors primarily in the following areas: regulation and competition, innovation, regional economy and industrial politics and health economics.

Research results are disseminated through publications, conferences and colloquia. These activities are aimed to foster cooperation between the private sector and public administrations, as well as the exchange of ideas and initiatives.

The sponsors of the Public-Private Sector Research Center are the following:

- Ajuntament de Barcelona

- Departament d' Economia i Coneixement de la Generalitat de Catalunya

- Departament d' Empresa i Ocupació de la Generalitat de Catalunya

- Diputació de Barcelona

- Fundació AGBAR

- Institut Català de les Empreses Culturals (ICEC)

- PricewaterhouseCoopers

- Sanofi

- FGC

The contents of this publication reflect the conclusions and findings of the individual authors, and not the opinions of the Center's sponsors. 


\title{
Who should pay for two-way interconnection?
}

\author{
Sjaak Hurkens and Ángel L. López*
}

July 18, 2014

\begin{abstract}
European and the US mobile communication services markets have developed in rather different ways. There are striking differences in termination regulation and retail pricing models and one may wonder why this occurred and whether either of the markets outperforms the other in terms of efficiency and/or profitability. We address these issues by analyzing a symmetric oligopoly model in which firms are able, but not obliged, to charge subscribers for receiving and placing calls, may discriminate between on- and off-net calls and may request a monthly subscription fee. We show that a continuum of equilibria exist for any reciprocal termination rate, some of which resemble the European business model (with zero charges for reception) while others resemble the US business model (with equal prices for placing and receiving calls). We show that under neither of these business models full efficiency can be achieved. Comparing the European business model with termination regulated at cost to the US business model with voluntary Bill and Keep arrangements we show that the European scenario is more efficient when call externality is modest, and more profitable when either call externality is modest and call demand elasticity high or call externality high and call demand elasticity low. Our predictions are consistent both with observed network operators' opposition to lowering termination rates in Europe and with voluntary agreements to Bill and Keep arrangements in the US.
\end{abstract}

${ }^{*}$ Hurkens: Institute for Economic Analysis (CSIC), BGSE, and Public-Private Sector Research Center (IESE Business School, University of Navarra, Spain), sjaak.hurkens@iae.csic.es. López: Departament d'Economia Aplicada (UAB), and Public-Private Sector Research Center (IESE Business School, University of Navarra, Spain), AngelLuis.Lopez@uab.cat. We thank Stefan Behringer, Carlo Cambini, Steffen Hoernig, Keizo Mizuno, Francesc Trillas, Tommaso Valletti and João Vareda for helpful discussions. Hurkens gratefully acknowledges financial support from the Spanish Ministry of Economy and Competitiveness, through grant ECO2012-37065 and through the Severo Ochoa Programme for Centres of Excellence in R\&D (SEV2011-0075). López gratefully acknowledges financial support from the Spanish Ministry of Economy and Competitiveness, through grant ECO2011-29533. Both authors gratefully acknowledge financial support from the Net Institute, http://www.Netinst.org. A previous draft of this paper was circulated under the title "Mobile Termination and Consumer Expectations under the Receiver-Pays Regime". 


\section{Introduction}

The liberalization of telecommunication markets has undoubtedly led to increased consumer surplus through higher quality service, lower prices and more variety. At the same time the need for heavy-handed regulation of retail prices of incumbent monopolists was eliminated. However, it also brought about new regulatory issues, such as the one of interconnection. Whenever a customer of operator A wants to call a customer of operator B, the latter has to provide a wholesale service called 'call termination'. Call termination is in fact a matter of two-way access because customers of B will also want to call customers of A. Who should pay for this two-way access? And, how much?

It is generally accepted that there is some role for regulatory intervention in the market for termination but there is no global consensus about the optimal intervention. (See also Valletti and Houpis, 2005). The European Commission argues that any (fixed and mobile) network has monopoly power in the market for termination on that network, and may be subject to regulation of the access price (or termination charge). It currently recommends national regulatory authorities to set charges based on cost. In the US, on the other hand, the FCC has chosen to let networks that require interconnection to negotiate bilaterally a reciprocal termination charge. Only in case of disagreement termination charges are imposed by the regulator. Such disagreements mainly occurred when one of the networks involved is an incumbent local exchange carrier (ILEC), in which case the regulator typically sets termination charge equal to the (very low) termination cost of the ILEC. In most other cases networks voluntarily agree on low or even zero termination charges (Bill and Keep). ${ }^{1}$

European and US telecommunication markets do not only differ in the approach to regulating termination but also in the business models that operators use. While in the US the Receiving Party Pays (RPP) regime is used, in Europe a Calling Party Pays (CPP) regime is in place. RPP means that operators charge a price to their customers not only for placing calls but also one for receiving calls. Consumers are willing to answer calls and pay reception charges only if they enjoy receiving calls, that is, if there is a call externality. The business model employed is closely linked to the approach to termination. Termination can be considered as a two-sided market where the terminating operator may charge both the originating operator and the recipient of the call, because both sides benefit from the termination service. It is not uncommon in two-sided markets that only one of the sides is charged a positive price. If termination charges are low (by agreement or regulation) operators may want to charge own customers for receiving calls, while if termination charges are

\footnotetext{
${ }^{1}$ Taken as given that traffic between an ILEC and any other operator will be terminated at cost, the arbitrage opportunity of transiting a call between two mobile networks through an ILEC may limit the feasible range of agreements on termination charges between the mobile networks severely.
} 
high and profit is made on termination services, operators may not want to charge customers for receiving calls in order not to reduce the volume of termination service.

RPP and CPP regimes produce rather different results. Littlechild (2006) shows empirically that RPP countries have lower usage prices and higher usage than CPP countries, but higher fixed fees (or lower hand-set subsidies) and perhaps lower penetration rates or at least slower growth in penetration rates. Dewenter and Kruse (2011) argue that penetration rates in CPP and RPP countries are not significantly different once one controls for endogenous regulation, i.e., once one takes into account that regulatory interventions may depend on the performance of the market and political or institutional factors. The seeming superiority of $\mathrm{RPP}$ has led some economists to call upon regulators in CPP countries to impose an RPP regime. ${ }^{2}$ However, the statistical evidence of correlations between the payment regimes, termination charges, penetration, and retail prices does not imply there is a specific causal relationship. It is not clear that adopting the receiver-pays regime will bring all the benefits that seem to be correlated with it. Could it be that the US RPP regime leads to too low prices and too high call volume? Even if the receiver-pays regime were superior from a social welfare point of view, it is difficult to imagine that regulators can actually force firms to use such specific retail pricing structure. Regulators can at most influence the choice of firms between the two regimes by either setting adequate termination rates or by letting firms negotiate reciprocal termination charges. It is thus necessary to understand how termination charges affect both efficiency and profitability of the retail market when firms are free to decide whether and how much to charge consumers for placing and receiving calls.

To explore this issue we extend the duopoly model by Jeon et al. (2004) (henceforth, JLT) where firms compete by setting non-negative on- and off-net prices for placing and receiving calls and a fixed fee to an oligopoly. We assume that consumers form passive expectations about network sizes, rather than responsive expectations as implicitly assumed in JLT. ${ }^{3}$ In any equilibrium on-net prices always lead to fully efficient on-net traffic, independent of the termination charge. However, for any particular termination charge there exists a continuum of equilibria that differ in the prices for off-net calls and fixed fees. We then analyze the properties of the set of all equilibrium prices that can prevail for some termination charge. We show that there exists at most one equilibrium that leads to efficient usage for off-net traffic. This equilibrium requires off-net prices such that caller and receiver share the total cost of a call in the same proportion they benefit from it. This equilibrium only exists for one value of the termination charge, which depends on this proportion (i.e., call externality).

\footnotetext{
${ }^{2}$ See for example de Bijl et al. (2005).

${ }^{3}$ We elaborate on the meaning and importance of this assumption when we lay out the model and in section 5 .
} 
This termination charge is strictly positive ${ }^{4}$ but below the cost of termination. Any other equilibrium leads to inefficiently low call volume. The efficient equilibrium can only exist when there are at least three firms. In the case of duopoly, firms have incentives to provoke connectivity breakdown by setting infinitely high reception charges, as was shown by JLT. Despite our efficiency possibility result, resorting to an industry with at least three firms does not resolve the issue fully.

First, even if regulators can calculate and set the necessary termination charge, there is no guarantee that firms will play the efficient equilibrium. In particular, when firms coordinate on the equilibrium where reception is free of charge (we call this the CPP equilibrium), as firms do in Europe, efficiency is impossible. Similarly, if firms play the equilibrium with equal price for placing and receiving calls (we call this the RPP* equilibrium), as is done in the US, efficiency is impossible. However, if other equilibrium selection criteria are used, efficiency may obtain when the regulator sets the required termination charge. For example, if firms play the equilibrium that is robust to adding vanishing noise to the receiver's marginal utility (as in JLT), the efficient equilibrium is played. Also, if firms coordinate on the profit maximizing equilibrium for a given termination charge, efficiency results.

Second, firms may want to agree on termination charges strictly below the one that is compatible with efficiency. For example, Bill and Keep may yield equilibrium prices that lead to higher industry profit but lower total welfare. This is true if firms play the equilibrium with equal prices for placing and receiving calls, the equilibrium robust to vanishing noise, or the joint profit maximizing equilibrium. Hence, neither a regulator setting a ceiling for termination charges nor letting firms negotiate reciprocal termination charges will lead to efficiency.

Our general results highlight the serious difficulty of achieving first-best outcomes. In particular, neither the European nor the US approach can lead to full efficiency. However, it is an interesting question to see whether the European or the US approach is better in terms of consumer, producer or total surplus. In particular, we compare consumer, producer and total surplus in the CPP equilibrium with termination priced at cost (which is the objective of the European Commission) with the RPP* equilibrium under Bill and Keep (which is and has been the main scenario in the US). The comparisons depend on call externality, the number of firms and the elasticity of call demand. Consumer and total surplus are higher under the European scenario for relatively low (but not implausible) values of the call externality. Producer surplus is higher under the European scenario in two distinct regions: for low call externality and high elasticity and for high call externality and low elasticity.

This paper is certainly not the first to investigate the impact of termination rates on

\footnotetext{
${ }^{4}$ Under the assumption that termination cost resembles half the cost of a call.
} 
competition between telecommunication networks. Let us now explain how this paper contributes and relates to the existing literature. This burgeoning literature starts with the seminal works of Armstrong (1998) and Laffont et al. (1998 a,b) $)^{5}$ where consumer derive no utility from receiving calls and firms always employ a CPP regime. Relatively few papers provide an analysis of competing firms under a RPP regime. Regarding the literature on CPP, Laffont et al. (1998b) consider the case when networks compete in nonlinear prices and can charge different price for on- and off-net calls, as we do. They show that profit is strictly decreasing in termination charge. Building on their analysis, Gans and King (2001) show that firms using a caller-pays regime strictly prefer below cost termination charges. The intuition for their results is that if termination charge is above cost, off-net calls will be more expensive than on-net calls. As there is a price differential between on- and off-net calls, consumers care about the size of each network (the so-called 'tariff-mediated network externalities'). In particular, they will be more eager to join the larger network. Consequently, acquisition costs are reduced, which in turn intensifies competition for subscribers and results in lower subscription fees and profits. Firms would thus prefer termination charges below cost. Berger (2005) considers the same CPP setting but allows for call externalities. He shows that the social welfare maximizing termination charge is then also strictly below cost. Moreover, for sufficiently strong call externality both firms and regulator prefer Bill and Keep over any positive termination charge.

These theoretical results are at odds with real world observations since regulators around the world, and especially in Europe, are concerned about too high termination charges and operators consistently oppose cutting termination rates. ${ }^{6}$ It is worth mentioning that a few recent papers reconcile real world observations with theory by changing the Laffont et al. (1998b) model in various ways (but still insist on zero prices for reception) and then show that firms do prefer termination rates above cost. In particular, in Hurkens and López (2014) we do this by assuming that consumers have passive expectations about network sizes. We show there that industry profit is increasing in termination charge and that efficiency is obtained when termination is priced below cost (when call externalities exist). The present paper also assumes passive expectations and shows that if firms are allowed to charge for reception, the efficient CPP equilibrium ceases to be an equilibrium because firms would necessarily charge a strictly positive price for reception if allowed to do so. Other papers that give explanations

\footnotetext{
${ }^{5}$ For a complete review of the literature on access charges see Armstrong (2002), Vogelsang (2003) and Peitz et al. (2004).

${ }^{6}$ Nevertheless, this result has been shown to be very robust. For example, it holds for any number of networks (Calzada and Valletti, 2008) and when networks are asymmetric (López and Rey, 2012). Also, Hurkens and Jeon (2012) show that this result holds when there are both network externalities (i.e., elastic subscription demand as in Dessein, 2003) and network-based price discrimination.
} 
for why firms object against lowering termination charges are Armstrong and Wright (2009), Hoernig et al. (2014), and Jullien et al. (2013). ${ }^{7}$

An incipient literature has started to examine the relationship between termination rates and equilibrium prices in an environment with call externalities and RPP regimes. The papers closest to ours are JLT, Cambini and Valletti (2008), López (2011) and Hoernig (2012). ${ }^{8}$ Our model is an oligopoly extension of JLT and assumes passive rather than responsive expectations. JLT use the vanishing noise criterion to address the issue of multiplicity and notice that efficiency cannot be attained because of connectivity breakdown. López (2011) generalizes this result to an asymmetric duopoly. Cambini and Valletti (2008) resolve the problem of connectivity breakdown by adding call propagation to the JLT model. Moreover, they show that when firms bargain about a reciprocal termination charge, agreement will be reached on the efficient one. We tackle the connectivity breakdown by considering an oligopoly and show that firms will not agree on the efficient charge when consumers have passive expectations. ${ }^{9}$ In section 5 we come back to the role of expectations. An important further contribution of our paper is that we characterize all equilibria and do not limit the attention to equilibria that are robust to adding vanishing noise. This allows us to compare the European and US telecommunication markets in terms of efficiency and profitability.

Our paper proceeds as follows. Section 2 generalizes the model of JLT by considering a Logit formulation with any number of networks. It also defines the concept of passive expectations. In section 3 we derive the set of equilibria and discuss its properties. Section 4 discusses four equilibrium selection hypotheses and, for each of them, the privately and socially optimal termination mark-ups. We also compare the European scenario of CPP with cost-based termination with the US scenario of RPP and Bill and Keep arrangements. Section 5 examines the role of passive versus responsive expectations. Section 6 concludes. The appendix collects some of the lengthier proofs.

\section{The model}

We consider a general model of $n \geq 2$ network operators. The $n$ network operators have complete coverage and compete for a continuum of consumers of unit mass.

\footnotetext{
${ }^{7}$ The three papers have in common that they add a realistic feature (expansion in the mobile market and uniform FTM and MTM termination rates, unbalanced calling patterns, elastic subscription for those consumers who only enjoy receiving calls) to the theoretical model and conclude that, for some parameter range, firms prefer termination charges above cost. They also conclude that efficient termination charges are above cost so that the need for regulation is mitigated.

${ }^{8}$ Other related papers in this literature include Kim and Lim (2001), Hermalin and Katz (2001, 2004, 2011), DeGraba (2003), Hahn (2003), Laffont et al. (2003), Berger (2004, 2005).

${ }^{9}$ Hoernig (2012) also shows that breakdown only occurs for the duopoly case.
} 
Timing. We assume that the terms of interconnection are negotiated or established by a regulator first. Then, for a given reciprocal ${ }^{10}$ access charge $a \geq 0$, the timing of the game is the following:

1. Consumers form expectations about the number of subscribers of each network $i$ : $\beta_{i}$.

2. Firms take these expectations as given and choose simultaneously retail tariffs.

3. Consumers make rational subscription and consumption decisions, given their expectations and given the networks' tariffs.

Consumers form expectations before tariffs are set. Consumers thus hold passive expectations which do not change when a firm changes a price. Realized market share $\alpha_{i}$ is a function of prices and consumer expectations. Self-fulfilling expectations imply that at equilibrium $\beta_{i}=\alpha_{i}$. In a symmetric equilibrium, expected and realized market shares are equal to $1 / n .^{11}$

Cost structure. The fixed cost to serve each subscriber is $f$, whereas $c_{O}$ and $c_{T}$ denote the marginal cost of providing a telephone call borne by the originating and terminating networks. The marginal cost of an on-net call is $c=c_{O}+c_{T}$. Let us denote the termination mark-up by

$$
m=a-c_{T}
$$

The perceived marginal cost of an off-net call for the originating network is the true cost $c$ for on-net calls, augmented by the termination mark-up for the off-net calls: $c_{O}+a=c+m$. The perceived marginal cost of an off-net call for the terminating network is $c_{T}-a=-m$.

Pricing. Each firm $i \in N=\{1,2, \ldots, n\}$ charges a tariff $T_{i}=\left(F_{i}, p_{i}, r_{i}, \hat{p}_{i}, \hat{r}_{i}\right)$, consisting of a fixed fee $\left(F_{i}\right)$, per-unit call and reception charges for on-net traffic $\left(p_{i}\right.$ and $\left.r_{i}\right)$ and per-unit call and reception charges for off-net traffic $\left(\hat{p}_{i}\right.$ and $\left.\hat{r}_{i}\right){ }^{12}$

Individual demand. Subscribers obtain positive utility from making and receiving calls. The caller's utility from making a call of length $q$ minutes is $u(q)$, whereas the receiver's is

\footnotetext{
${ }^{10}$ Reciprocity means that a network pays as much for termination of a call on the rival network as it receives for completing a call originated on the rival network.

${ }^{11}$ If consumers form expectations after tariffs are observed (as assumed in JLT), consumers' expectations are responsive because they would depend on the prices chosen. In Section 5 we compare the outcomes under passive and responsive expectations.

${ }^{12}$ When $n \geq 3$, it would be even more general to allow each firm to set different prices for off-net traffic depending on which network is being called or is calling. However, since attention will be restricted to symmetric equilibria we lose nothing from imposing that there cannot be discrimination between the prices set for traffic terminating or originating at different rival networks. This reduces the burden of notation.
} 
$\widetilde{u}(q)$ from receiving a call of that length. $u(\cdot)$ and $\widetilde{u}(\cdot)$ are twice continuously differentiable, increasing and concave. For tractability, we assume that

$$
\widetilde{u}(q)=\beta u(q) \quad \text { with } 0<\beta<1
$$

where $\beta$ measures the strength of the call externality. The caller's demand function is given by $u^{\prime}(q(p))=p$, whereas the receiver's demand function is given by $\widetilde{u}^{\prime}(q(r))=r$. We consider the case in which both callers and receivers can hang up. Defining $D(p, r)=q(\max \{p, r / \beta\})$, the length of an on-net call is $D\left(p_{i}, r_{i}\right)$, whereas the length of an off-net call is $D\left(\hat{p}_{i}, \hat{r}_{j}\right)$ (for $i \in N$ and $j \in(N \backslash\{i\}))$. We will denote $U(p, r)=u(D(p, r))$ and $\widetilde{U}(p, r)=\beta u(D(p, r))$.

Market shares. We are interested in allowing for industry structure with more than two firms. We will use the Logit formulation. ${ }^{13}$ We make the standard assumption of a balanced calling pattern, which means that the fraction of calls from a given subscriber of a given network and completed on another given (including the same) network is equal to the fraction of consumers subscribing to the terminating network. ${ }^{14}$ Let $w_{i}$ denote the expected value of subscribing to network $i$. That is,

$$
\begin{aligned}
w_{i}= & \beta_{i}\left(U\left(p_{i}, r_{i}\right)+\widetilde{U}\left(p_{i}, r_{i}\right)-\left(p_{i}+r_{i}\right) D\left(p_{i}, r_{i}\right)\right)-F_{i} \\
& +\sum_{j \neq i} \beta_{j}\left(U\left(\hat{p}_{i}, \hat{r}_{j}\right)-\hat{p}_{i} D\left(\hat{p}_{i}, \hat{r}_{j}\right)\right) \\
& +\sum_{j \neq i} \beta_{j}\left(\widetilde{U}\left(\hat{p}_{j}, \hat{r}_{i}\right)-\hat{r}_{i} D\left(\hat{p}_{j}, \hat{r}_{i}\right)\right)
\end{aligned}
$$

The first line corresponds to the utility from placing and receiving on-net calls, the second to the utility from placing off-net call and the third to the utility from receiving off-net calls. Consumers have idiosyncratic tastes for each operator. So we add a random noise term $\varepsilon_{i}$ and define $U_{i}=w_{i}+\mu \varepsilon_{i}$. The parameter $\mu>0$ reflects the degree of product differentiation in a Logit model. A high value of $\mu$ implies that most of the value is determined by a random draw so that competition between the firms is rather weak. The noise terms $\varepsilon_{k}$ are random variables of zero mean and unit variance, identically and independently double exponentially distributed. These terms reflect consumers' preference for one good over another (they are known to the consumer but are unobserved by the firms). A consumer will subscribe to network $i \in N$ if and only if $U_{i}>U_{j}$ for all $j \in N \backslash\{i\}$. The probability of subscribing to

\footnotetext{
${ }^{13}$ See Anderson and de Palma (1992) and Anderson et al. (1992) for more details about the Logit model.

${ }^{14}$ Dessein $(2003,2004)$ examines how unbalanced calling patterns between different customer types affect retail competition when network operators compete in the presence of the caller-pays regime.
} 
network $i$ is denoted by $\alpha_{i}$. The probabilities (or equivalently, market shares) are given by

$$
\alpha_{i}=\frac{\exp \left[w_{i} / \mu\right]}{\sum_{k=1}^{n} \exp \left[w_{k} / \mu\right]} .
$$

Consumer Surplus. Consumer surplus in the Logit model has been derived by Small and Rosen (1981) as (up to a constant)

$$
C S=\mu \ln \left(\sum_{k=1}^{n} \exp \left(w_{k} / \mu\right)\right)=w+\mu \ln n,
$$

where the last equation holds in case of a symmetric solution where each network offers surplus $w_{i}=w$.

\section{$3 \quad$ Symmetric equilibrium analysis}

It is straightforward to see that there always exists an equilibrium without any off-net traffic. All firms charging infinite call and reception prices for off-net traffic constitutes part of an equilibrium. On-net prices will be set efficiently and fixed fees are used to fight for market share. Firms will not make any profit on call and reception services and just choose fixed fee to maximize $\pi=\alpha(F-f)$. In a symmetric equilibrium this yields $F^{*}=f+n \mu /(n-1)$ and profit $\pi^{*}=\mu /(n-1)$. There may also exist equilibria in which off-net traffic is choked off by infinite reception charges only.

We will, however, focus on symmetric equilibria without connectivity breakdown so that off-net call volume is strictly positive. Of course, we do take into account that each network could choke off inbound or outbound off-net traffic. That is, we need to make sure that firms have no incentives to choke off off-net traffic.

Firms will set on-net call and reception charges so as to maximize the utility obtained from on-net traffic by internalizing the call externality. Optimality requires that the volume of on-net traffic $q$ satisfies $(1+\beta) u^{\prime}(q)=c$. This can be obtained by setting prices $\left(p^{*}, r^{*}\right)$ where

$$
p^{*}=\frac{c}{1+\beta}, \quad r^{*}=\frac{\beta c}{1+\beta} .
$$

Of course, the optimal volume can also be obtained by setting on-net prices $\left(p^{*}, r_{i}\right)$ with $r_{i}<r^{*}$ or $\left(p_{i}, r^{*}\right)$ with $p_{i}<p^{*}$. We will assume (for now and without loss of generality) that prices $\left(p^{*}, r^{*}\right)$ are chosen. ${ }^{15}$ Note that $p^{*}+r^{*}=c$ so that no profit is obtained from on-net

\footnotetext{
${ }^{15}$ If there would be vanishing noise in the receiver's utility then the unique optimal prices would converge
} 
traffic (except for the fixed fee that is levied on subscribers). Note that at prices $p^{*}$ and $r^{*}$ caller and receiver share the cost of a call in the proportion they benefit from it. These prices will also play a role when we discuss efficient off-net prices.

Determining the equilibrium prices for off-net traffic from and to network $i$ is more complicated because these prices $\hat{p}_{i}$ and $\hat{r}_{i}$ not only affect own subscribers, but also consumers on other networks through the call externality: if a reduction in $\hat{p}_{i}$ raises call volume, consumers on rival networks will receive (and pay for) more calls; if a reduction in $\hat{r}_{i}$ raises call volume, consumers on rival networks will place (and pay for) more calls. Even if one focuses on symmetric equilibria in which the caller determines the volume of off-net calls, the actual level of $\hat{r}_{j}$ is important to determine the optimal $\hat{p}_{i}$. Similarly, even if one focuses on symmetric equilibria in which the receiver determines the volume of off-net calls, the actual level of $\hat{p}_{i}$ is relevant to determine the optimal $\hat{r}_{j}$. We analyze these equilibria in turn in the next subsections. We first determine necessary local conditions for a symmetric equilibrium without connectivity breakdown. Later we formulate sufficient conditions under which the candidate equilibrium strategies are global best replies, so that they indeed constitute an equilibrium.

\subsection{Call volume determined by caller}

We fix $\hat{r}_{i}=\hat{r}^{*}$ for all $i \in N$. We look for a symmetric equilibrium so that expected market shares equal $\beta_{i}=1 / n$ for all $i$. Since subscription demand is assumed inelastic and the off-net call price $\hat{p}_{i}$ will affect all rivals in the same way (in a symmetric equilibrium), one can calculate the optimal off-net call price of network $i$ by keeping market shares constant (by adjusting $F_{i}$ accordingly). Fixing $\hat{p}_{j}=\hat{p}^{*}$ and $F_{j}=F^{*}$ for all $j \neq i$, the profit of network $i$ is equal to

$$
\pi_{i}=\alpha_{i}\left[\left(1-\alpha_{i}\right)\left(\hat{p}_{i}-c-m\right) q\left(\hat{p}_{i}\right)+\left(1-\alpha_{i}\right)\left(\hat{r}^{*}+m\right) q\left(\hat{p}^{*}\right)+F_{i}-f\right]
$$

where $F_{i}$ is such that the expected surplus from subscribing to network $i$ is equal to the expected surplus from subscribing to any other network:

$$
\begin{aligned}
F_{i} & =\frac{n-1}{n}\left[\left(u\left(q\left(\hat{p}_{i}\right)\right)-\hat{p}_{i} q\left(\hat{p}_{i}\right)\right)-\left(u\left(q\left(\hat{p}^{*}\right)\right)-\hat{p}^{*} q\left(\hat{p}^{*}\right)\right)\right] \\
& +\frac{1}{n}\left[\left(\beta u\left(q\left(\hat{p}^{*}\right)\right)-\hat{r}^{*} q\left(\hat{p}^{*}\right)\right)-\left(\beta u\left(q\left(\hat{p}_{i}\right)\right)-\hat{r}^{*} q\left(\hat{p}_{i}\right)\right)\right]+F^{*} .
\end{aligned}
$$

to $\left(p^{*}, r^{*}\right)$. This is formally shown in the proof of Proposition 9 below. 
Observe that

$$
\frac{\partial F_{i}}{\partial \hat{p}_{i}}=\frac{n-1}{n}\left[-q\left(\hat{p}_{i}\right)\right]-\frac{1}{n}\left[\left(\beta \hat{p}_{i}-\hat{r}^{*}\right) q^{\prime}\left(\hat{p}_{i}\right)\right] .
$$

The first-order condition reads

$$
\begin{aligned}
0=\frac{\partial \pi_{i}}{\partial \hat{p}_{i}} & =\alpha_{i}\left[\left(1-\alpha_{i}\right)\left[q\left(\hat{p}_{i}\right)+\left(\hat{p}_{i}-c-m\right) q^{\prime}\left(\hat{p}_{i}\right)\right]-\frac{n-1}{n} q\left(\hat{p}_{i}\right)-\frac{1}{n}\left(\beta \hat{p}_{i}-\hat{r}^{*}\right) q^{\prime}\left(\hat{p}_{i}\right)\right] \\
& =\alpha_{i} q^{\prime}\left(\hat{p}_{i}\right)\left[\left(1-\alpha_{i}\right)\left(\hat{p}_{i}-c-m\right)-\frac{1}{n}\left(\beta \hat{p}_{i}-\hat{r}^{*}\right)\right]+\alpha_{i} q\left(\hat{p}_{i}\right)\left(\frac{1}{n}-\alpha_{i}\right),
\end{aligned}
$$

so that in a symmetric equilibrium (where $\alpha_{i}=1 / n$ ), we must have

$$
(n-1-\beta) \hat{p}_{i}-(n-1)(c+m)+\hat{r}^{*}=0 .
$$

Note that the second-order derivative of profits, evaluated at the solution of the first-order condition, reads

$$
\frac{\partial^{2} \pi_{i}}{\partial \hat{p}_{i}^{2}}=\frac{q^{\prime}\left(\hat{p}_{i}\right)}{n^{2}}(n-1-\beta)<0
$$

for all $\beta<1$ and $n \geq 2$. Hence, in a symmetric equilibrium in which callers determine the volume of calls, we must have

$$
\hat{p}^{*}=\frac{(n-1)(c+m)-\hat{r}^{*}}{n-1-\beta}
$$

and $0 \leq \hat{r}^{*} \leq \beta \hat{p}^{*}$ or, equivalently, $0 \leq \hat{r}^{*} \leq \beta(c+m)$. Substituting these prices into the profit function yields

$$
\pi_{i}=\alpha_{i}\left[\left(1-\alpha_{i}\right)\left(\hat{p}^{*}+\hat{r}^{*}-c\right) q\left(\hat{p}^{*}\right)+F_{i}-f\right] .
$$

To find the equilibrium fixed fee we solve the first-order condition ${ }^{16}$

$$
0=\frac{\partial \pi_{i}}{\partial F_{i}}=-\frac{\alpha_{i}\left(1-\alpha_{i}\right)}{\mu}\left(\left(1-2 \alpha_{i}\right)\left(\hat{p}^{*}+\hat{r}^{*}-c\right) q\left(\hat{p}^{*}\right)+F_{i}-f\right)+\alpha_{i} .
$$

At a symmetric equilibrium $\alpha_{i}=1 / n$ so that equilibrium fixed fee satisfies

$$
F^{*}=f+\frac{n \mu}{n-1}-\frac{n-2}{n}\left(\hat{p}^{*}+\hat{r}^{*}-c\right) q\left(\hat{p}^{*}\right),
$$

\footnotetext{
${ }^{16}$ We use here that $\partial \alpha_{i} / \partial F_{i}=-\alpha_{i}\left(1-\alpha_{i}\right) / \mu$ from Eq. (1).
} 
and equilibrium profit equals

$$
\pi^{*}=\frac{\mu}{n-1}+\frac{1}{n^{2}}\left(\hat{p}^{*}+\hat{r}^{*}-c\right) q\left(\hat{p}^{*}\right)
$$

Note that condition (5) is necessary but not quite sufficient. In particular, one needs to check whether a network has an incentive to raise the reception charge for off-net calls above $\beta \hat{p}^{*}$. The next lemma shows that when either $\beta \hat{p}^{*}<-m$ or $\beta \hat{p}^{*}=-m$ and $(n-1) \beta<1$, the firm certainly has an incentive to deviate by setting reception price marginally above $\beta \hat{p}^{*}$. On the other hand, when $\beta \hat{p}^{*} \geq-m,(n-1) \beta>1$ and product differentiation parameter $\mu$ is sufficiently high, then the firm has no incentive to deviate and the candidate equilibrium is in fact an equilibrium.

Lemma 1 A necessary condition for $\left(\hat{p}^{*}, \hat{r}^{*}\right)$ as defined in (5) to be off-net usage prices in a symmetric equilibrium in which the caller determines call volume is that $\beta \hat{p}^{*} \geq-m$. When $(n-1) \beta>1$ and the product differentiation parameter $\mu$ is sufficiently high, this necessary condition is also sufficient.

Proposition 2 [Caller determined volume]

[i] If $\left(p^{*}, r^{*}, \hat{p}^{*}, \hat{r}^{*}, F^{*}\right)$ is a symmetric equilibrium in which the caller determines the call volume, then $\hat{p}^{*}, \hat{r}^{*}$ and $F^{*}$ must satisfy

$$
\begin{aligned}
\hat{p}^{*} & =\frac{(n-1)(c+m)-\hat{r}^{*}}{n-1-\beta} \geq \max \left\{-m / \beta, \hat{r}^{*} / \beta\right\} \\
F^{*} & =f+\frac{n \mu}{n-1}-\frac{n-2}{n}\left(\hat{p}^{*}+\hat{r}^{*}-c\right) q\left(\hat{p}^{*}\right)
\end{aligned}
$$

[ii] If $\hat{p}^{*}, \hat{r}^{*}$ and $F^{*}$ satisfy the conditions in [i], $(n-1) \beta>1$ and $\mu$ is sufficiently high, then $\left(p^{*}, r^{*}, \hat{p}^{*}, \hat{r}^{*}, F^{*}\right)$ is a symmetric equilibrium in which the caller determines the call volume, and equilibrium profit equals

$$
\pi^{*}=\frac{\mu}{n-1}+\frac{1}{n^{2}}\left(\hat{p}^{*}+\hat{r}^{*}-c\right) q\left(\hat{p}^{*}\right)
$$

Notice that the number of firms is relevant when checking whether a firm has an incentive to create connectivity breakdown by raising the off-net reception price to infinity. If the number of firms is high (so that $\beta>1 /(n-1)$ ) there is no incentive to do this. The intuition is clear: if network $i$ provokes connectivity breakdown this will affect the subscribers of other networks only with respect to the calls made to subscribers of network $i$. This is only a (small) fraction $1 /(n-1)$ of all off-net calls made. On the other hand, the subscribers of 
network $i$ will not be able to receive any off-net call. As long as $\beta>1 /(n-1)$ connectivity breakdown hurts subscribers from network $i$ more than those of rival networks.

If, on the other hand, $(n-1) \beta<1$, provoking connectivity breakdown by unilaterally setting reception charge equal to infinity may (but need not) be a profitable deviation from the proposed price schedule. In particular, if $n=2$ the sufficient condition in part [ii] of Proposition 2 is never satisfied and one needs to check carefully whether provoking connectivity breakdown is a profitable deviation from the proposed prices. The profitability of such a deviation depends on the particular equilibrium candidate under consideration, the termination charge, and the strength of the call externality. In particular, provoking connectivity breakdown will be profitable for low values of the call externality, but not for very high ones.

As a first example, consider a duopoly and suppose that $-\beta c /(1+\beta)<m \leq 0$. Consider the candidate equilibrium off-net prices $(\hat{p}, \hat{r})=((c+2 m) /(1-\beta),-m)$. In this case no profit is made from receiving off-net calls because $\hat{r}+m=0$. By deviating to $\hat{r}_{1}=\infty$ network 1 hurts subscribers on the rival network more than its own subscribers when the call externality is weak. As a result, it can raise the fixed fee to its own subscribers such that it still attracts half of the market. This clearly raises the profit of network 1 . On the other hand, when the call externality is strong ( $\beta$ close to 1 ) then provoking connectivity breakdown hurts own subscribers more than the rival's subscribers, because the caller pays more for off-net calls than the receiver does, while the utility obtained from such calls is almost the same for both parties.

As a second example, consider again a duopoly and suppose now that $m=0$. Consider the candidate equilibrium off-net prices $(\hat{p}, \hat{r})=(c, \beta c)$. Note that profit equals $\mu+\frac{1}{4} \beta c q(c)$. No profit is made on calls placed off-net (because $\hat{p}=c+m$ ) but profit is made on calls received off-net. Provoking connectivity breakdown will imply losing the latter profits. In fact, profit will equal $\pi_{1}=\alpha_{1}\left(F_{1}-f\right)$. The optimal fixed fee satisfies thus $F_{1}-f=\mu /\left(1-\alpha_{1}\right)$. To keep market share constant at $1 / 2$, network 1 can raise its fixed fee by $\frac{1}{2}(1-\beta) v(c)$ where $v(c)=u(q(c))-c q(c)$. It will be optimal to raise its fixed fee by a little less and increase market share above $1 / 2$. In any case, for $\beta$ sufficiently close to 1 the raise in fixed fee and market share will not be sufficient to compensate the loss of profits from receiving off-net calls. On the other hand, if the call externality is very weak, the raise in fixed fee is more than enough to recover the small loss of profits.

\subsection{Call volume determined by receiver}

We look for a symmetric equilibrium in which receivers determine the off-net call volume. Let us fix $\hat{p}_{i}=\hat{p}^{*}$ for all $i \in N$. Since subscription demand is assumed inelastic and the 
off-net reception price $\hat{r}_{i}$ will affect all rivals in the same way (in a symmetric equilibrium), one can calculate the optimal off-net reception price of network $i$ by keeping market shares constant by adjusting $F_{i}$ accordingly. Fixing $\hat{r}_{j}=\hat{r}^{*}$ and $F_{j}=F^{*}$ for all $j \neq i$, the profit of network $i$ is equal to

$$
\pi_{i}=\alpha_{i}\left[\left(1-\alpha_{i}\right)\left(\hat{p}^{*}-c-m\right) q\left(\hat{r}^{*} / \beta\right)+\left(1-\alpha_{i}\right)\left(\hat{r}_{i}+m\right) q\left(\hat{r}_{i} / \beta\right)+F_{i}-f\right]
$$

where $F_{i}$ is such that expected surplus from subscribing to network $i$ is equal to the expected surplus obtained from subscribing to any other network:

$$
\begin{aligned}
F_{i} & =\frac{n-1}{n}\left[\left(\beta u\left(q\left(\hat{r}_{i} / \beta\right)\right)-\hat{r}_{i} q\left(\hat{r}_{i} / \beta\right)\right)-\left(\beta u\left(q\left(\hat{r}^{*} / \beta\right)\right)-\hat{r}^{*} q\left(\hat{r}^{*} / \beta\right)\right)\right] \\
& +\frac{1}{n}\left[\left(u\left(q\left(\hat{r}^{*} / \beta\right)\right)-\hat{p}^{*} q\left(\hat{r}^{*} / \beta\right)\right)-\left(u\left(q\left(\hat{r}_{i} / \beta\right)\right)-\hat{p}^{*} q\left(\hat{r}_{i} / \beta\right)\right)\right]+F^{*} .
\end{aligned}
$$

Observe that

$$
\frac{\partial F_{i}}{\partial \hat{r}_{i}}=\frac{n-1}{n}\left[-q\left(\hat{r}_{i} / \beta\right)\right]-\frac{1}{n \beta^{2}}\left[\left(\hat{r}_{i}-\beta \hat{p}^{*}\right) q^{\prime}\left(\hat{r}_{i} / \beta\right)\right] .
$$

At a symmetric equilibrium (with market share $\alpha_{i}$ kept constant at $1 / n$ ) the derivative of profits w.r.t. $\hat{r}_{i}$ is

$$
\begin{aligned}
\frac{\partial \pi_{i}}{\partial \hat{r}_{i}} & =\frac{1}{n}\left[\frac{n-1}{n}\left[q\left(\hat{r}_{i} / \beta\right)+\left(\hat{r}_{i}+m\right) q^{\prime}\left(\hat{r}_{i} / \beta\right) / \beta-q\left(\hat{r}_{i} / \beta\right)\right]-\frac{1}{n}\left(\hat{r}_{i} / \beta-\hat{p}^{*}\right) q^{\prime}\left(\hat{r}_{i} / \beta\right) / \beta\right] \\
& =\frac{q^{\prime}\left(\hat{r}_{i} / \beta\right)}{\beta^{2} n^{2}}\left[(n-1) \beta\left(\hat{r}_{i}+m\right)-\hat{r}_{i}+\beta \hat{p}^{*}\right] .
\end{aligned}
$$

Hence, if $(n-1) \beta-1<0$ no interior solution exists and the optimal reception charge is either $\beta \hat{p}^{*}$ or $\infty$. In particular, for $n=2$ and $\beta<1$ no equilibrium exists without connectivity breakdown where only the receiver determines call volume.

If $(n-1) \beta-1=0$ a solution exists only if $\beta \hat{p}^{*}=-m$ (which requires $m \leq 0$ ). In this peculiar case any reception charge $\hat{r}^{*} \geq \beta \hat{p}^{*}$ satisfies the first-order condition.

If $(n-1) \beta-1>0$ a unique interior solution is given by

$$
(\beta(n-1)-1) \hat{r}_{i}+\beta(n-1) m+\beta \hat{p}^{*}=0
$$

Hence, in this case a symmetric equilibrium in which receivers determine the volume of calls must satisfy $0 \leq \hat{\beta} p^{*} \leq \hat{r}^{*}$ and

$$
\hat{r}^{*}=\frac{\beta\left((n-1) m+\hat{p}^{*}\right)}{1-(n-1) \beta} .
$$


Substituting the prices into the profit function and maximizing with respect to the fixed fee yields, as before

$$
F^{*}=f+\frac{n \mu}{n-1}-\frac{n-2}{n}\left(\hat{p}^{*}+\hat{r}^{*}-c\right) q\left(\hat{r}^{*} / \beta\right)
$$

so that equilibrium profit equals

$$
\pi^{*}=\frac{\mu}{n-1}+\frac{1}{n^{2}}\left(\hat{p}^{*}+\hat{r}^{*}-c\right) q\left(\hat{r}^{*} / \beta\right)
$$

Note that condition (9) is not yet quite sufficient, as one needs to check whether a network has an incentive to raise call price above $\hat{r}^{*} / \beta$. The next lemma addresses this question.

Lemma 3 Let $(n-1) \beta>1$. A necessary condition for $\left(\hat{p}^{*}, \hat{r}^{*}\right)$ as defined in (9) to be offnet usage prices in a symmetric equilibrium in which the receiver determines call volume is that $\hat{r}^{*} \geq \beta(c+m)$. For sufficiently high product differentiation parameter $\mu$, this necessary condition is sufficient. Such an equilibrium only exists for $m \leq \bar{m}^{R}$, where

$$
\bar{m}^{R}=\frac{[1-(n-1) \beta] c}{n-2+(n-1) \beta}<0 .
$$

Proposition 4 [Receiver determined volume]

[i] If $(n-1) \beta<1$ or $m>\bar{m}^{R}$, there exists no symmetric equilibrium in which the receiver determines the call volume.

[ii] If $(n-1) \beta>1, m \leq \bar{m}^{R}$, and $\mu$ is sufficiently high, then $\left(p^{*}, r^{*}, \hat{p}^{*}, \hat{r}^{*}, F^{*}\right)$ is a symmetric equilibrium in which the receiver determines the call volume if and only if $\hat{p}^{*}, \hat{r}^{*}$ and $F^{*}$ satisfy

$$
\begin{aligned}
\hat{r}^{*} & =\frac{\beta\left((n-1) m+\hat{p}^{*}\right)}{1-(n-1) \beta} \geq \max \left\{\beta(c+m), \beta \hat{p}^{*}\right\} \\
F^{*} & =f+\frac{n \mu}{n-1}-\frac{n-2}{n}\left(\hat{p}^{*}+\hat{r}^{*}-c\right) q\left(\hat{r}^{*} / \beta\right) .
\end{aligned}
$$

Moreover, equilibrium profit then equals

$$
\pi^{*}=\frac{\mu}{n-1}+\frac{1}{n^{2}}\left(\hat{p}^{*}+\hat{r}^{*}-c\right) q\left(\hat{r}^{*} / \beta\right) .
$$

Figure 1 illustrates the set of equilibrium off-net usage prices for a fixed $m$ when $(n-1) \beta>$ $1, m \leq \bar{m}^{R}$ and $\mu$ sufficiently high. Note the special role played by $\bar{m}$ where

$$
\bar{m}=\frac{-\beta c}{1+\beta} .
$$




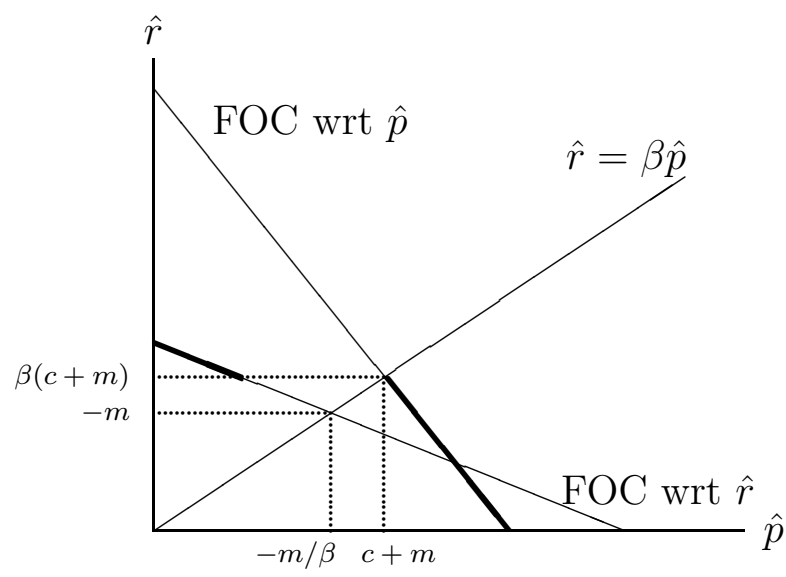

(a) $m>-\beta c /(1+\beta)$

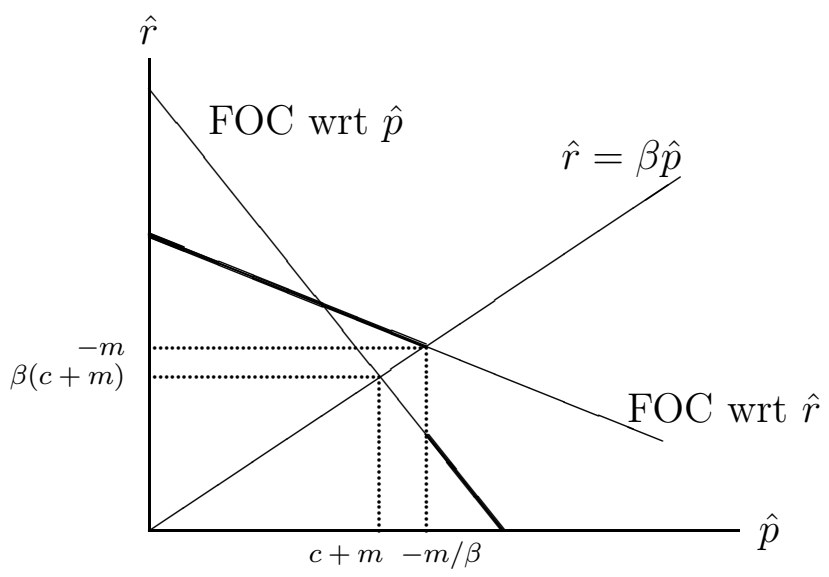

(b) $m<-\beta c /(1+\beta)$

Figure 1: Equilibrium off-net prices for a fixed termination mark-up $m$.

\subsection{Properties of the set of equilibria}

Propositions 2 and 4 establish for a particular termination mark-up $m$ the set of equilibria in which callers and receivers determine call volume. A continuum of equilibria exists for each $m$. Profit and welfare properties of the different equilibria depend on $m$ only through off-net prices $\hat{p}$ and $\hat{r}$. Performing policy analysis and recommending termination rates would require to know which equilibrium will be played. There is no unique obvious way of selecting one equilibrium. Before proposing four possible equilibrium selection criteria, we first investigate the set of all possible combinations of off-net call and reception charges that can prevail in an equilibrium for some termination mark-up. This will allow us to analyze whether and how efficiency can be obtained. Moreover, it will give some insight in the overall profitability of the different equilibria. Finally, it will allow us to clarify the similarity, or better, duality between caller determined and receiver determined call volume equilibria.

Let us denote by $E^{C}$ (resp. $E^{R}$ ) the set of off-net prices $(\hat{p}, \hat{r})$ in an equilibrium where callers (resp. receivers) determine the call volume. Because on-net prices are the same in all equilibria and equilibrium fixed fees are a function of off-net prices, we can identify equilibrium off-net prices with equilibria.

Let $(\hat{p}, \hat{r}) \in E^{C}$. Then the termination mark-up must equal $m^{C}(\hat{p}, \hat{r})$ where

$$
m^{C}(p, r)=\frac{(n-1-\beta) p+r}{n-1}-c
$$

Furthermore, necessary conditions are that $\beta \hat{p} \geq \hat{r} \geq 0$ and $\beta \hat{p} \geq-m^{C}(\hat{p}, \hat{r})$. Since we do 
not allow for negative termination charges a final necessary condition is that $m^{C}(\hat{p}, \hat{r}) \geq-c_{T}$. From Proposition 2 it follows that any pair $(\hat{p}, \hat{r})$ that satisfies the above conditions is part of an equilibrium when $(n-1) \beta>1$ and $\mu$ is sufficiently high.

Let now $(\hat{p}, \hat{r}) \in E^{R}$. These prices can only be part of such equilibrium when the termination mark-up equals $m^{R}(\hat{p}, \hat{r})$ where

$$
m^{R}(p, r)=\frac{((1-(n-1) \beta) r) / \beta-p}{n-1}
$$

Furthermore, necessary conditions are that $\hat{r} \geq \beta \hat{p} \geq 0$ and $\hat{r} \geq \beta\left(c+m^{R}(\hat{p}, \hat{r})\right)$. Since we do not allow for negative termination charges a final necessary condition is that $m^{R}(\hat{p}, \hat{r}) \geq-c_{T}$. From Proposition 4 it follows that any pair $(\hat{p}, \hat{r})$ that satisfies the above conditions is part of an equilibrium when $(n-1) \beta>1$ and $\mu$ is sufficiently high.

Thus we obtain the following corollary.

Corollary 5 Assume $(n-1) \beta>1$ and $\mu$ sufficiently high. Then the set of equilibrium off-net prices in an equilibrium with caller determined volume is

$$
E^{C}=\left\{(\hat{p}, \hat{r}) \in \Re_{+}^{2} \quad: \quad m^{C}(\hat{p}, \hat{r}) \geq-c_{T} \text { and } \beta \hat{p} \geq \max \left\{\hat{r},-m^{C}(\hat{p}, \hat{r})\right\}\right\}
$$

and the set of equilibrium off-net prices in an equilibrium with receiver determined volume is

$$
E^{R}=\left\{(\hat{p}, \hat{r}) \in \Re_{+}^{2} \quad: \quad m^{R}(\hat{p}, \hat{r}) \geq-c_{T} \text { and } \hat{r} \geq \max \left\{\beta \hat{p}, \beta\left[c+m^{R}(\hat{p}, \hat{r})\right]\right\}\right\} .
$$

Recall that $p^{*}$ and $r^{*}$ as defined in Eq. (3) are the efficient (on-net) prices. Note that $m^{C}\left(p^{*}, r^{*}\right)=m^{R}\left(p^{*}, r^{*}\right)=-\beta c /(1+\beta)=\bar{m}$ so that $\left(p^{*}, r^{*}\right) \in E^{C} \cap E^{R}$ if and only if $\beta c /(1+\beta) \leq c_{T}$, which we will assume to hold. Note that a sufficient condition for this is that $c_{T}=c / 2$. The sets $E^{C}$ and $E^{R}$ are illustrated in Figure 2.

Because the lines defined by $\beta \hat{p}=-m^{C}(\hat{p}, \hat{r})$ and $\hat{r}=\beta\left(c+m^{R}(\hat{p}, \hat{r})\right)$ are downward sloping and go through the point $\left(p^{*}, r^{*}\right)$, it follows that any pair of off-net equilibrium prices $(\hat{p}, \hat{r}) \neq\left(p^{*}, r^{*}\right)$ leads to inefficiently low call volume. Hence, even though any offnet prices $\hat{p}=p^{*}$ and $\hat{r}<\beta p^{*}$ (or $\hat{r}=r^{*}$ and $\hat{p}<r^{*} / \beta$ ) would yield efficient off-net call volume, none of these combinations can prevail in an equilibrium for any termination markup. In particular, any equilibrium with zero charge for reception must be inefficient and any equilibrium with $\hat{p}=\hat{r}$ must be inefficient.

Let us now consider the profitability of the different equilibrium outcomes. Consider an equilibrium with $\beta \hat{p}>\hat{r}$ and $\hat{p}+\hat{r}>c$. It is immediate that the equilibrium $(\hat{p}-\varepsilon, \hat{r}+\varepsilon)$ yields higher profit for small $\varepsilon>0$, because the strictly positive profit margin remains 


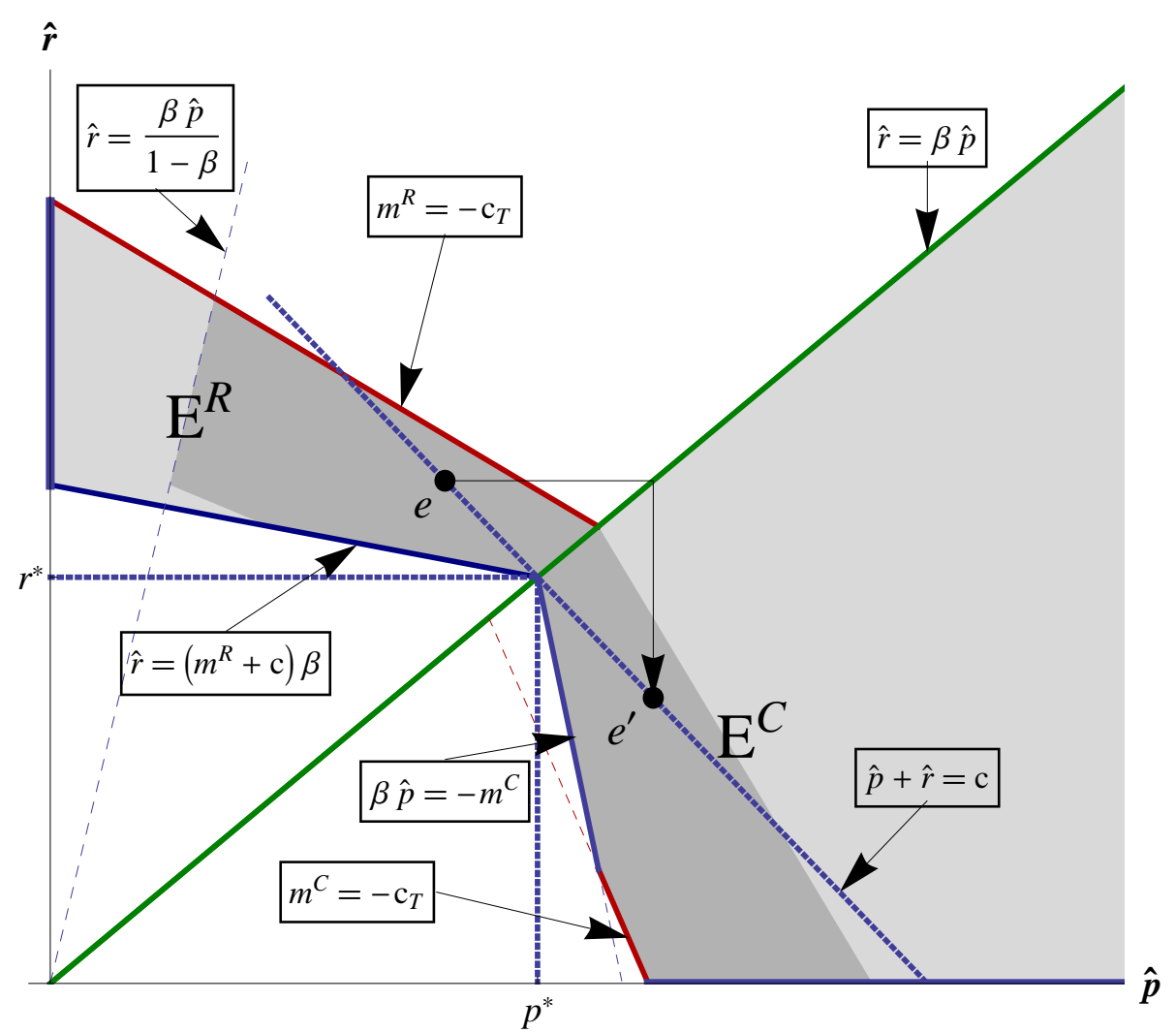

Figure 2: Off-net equilibrium prices in which caller $\left(E^{C}\right)$ or receiver $\left(E^{R}\right)$ determines call volume. For equilibrium prices in the dark shaded areas there exists a dual equilibrium in which the other party determines call volume.

the same while call volume increases. Hence, the maximum profit to be obtained in any equilibrium in which callers determine call volume is obtained for some equilibrium with $\beta \hat{p}=\hat{r}$. The same argument holds for the optimal payoff to be obtained in any equilibrium in which the receiver determines the call volume. Hence, the profit maximizing equilibrium must have $\hat{r}^{\pi}=\beta \hat{p}^{\pi}$ where $\hat{p}^{\pi}=\arg \max _{p}((1+\beta) p-c) q(p)$. In case of iso-elastic call demand, the maximum is obtained when $\hat{p}=p^{M} /(1+\beta)$, where $p^{M}=\arg \max _{p}\{(p-c) q(p)\}$ denotes the monopoly (call) price. Total price is equal to monopoly price but call volume is strictly higher than monopoly call volume. Note that $p^{\pi}>p^{*}$. The maximal profit can be achieved in a caller determined volume equilibrium when the termination mark-up is equal to $m^{C}\left(\hat{p}^{\pi}, \hat{r}^{\pi}\right)>\bar{m}$, and possibly also in a receiver determined volume equilibrium when the termination mark-up equals $m^{R}\left(\hat{p}^{\pi}, \hat{r}^{\pi}\right)<\bar{m}$. However, the latter may be below $-c_{T}$ which would require a negative termination charge, that is, a payment from the terminating network to the originating network which is not allowed for in our model.

Let us summarize our results. 


\section{Proposition 6}

[i] The total welfare maximizing equilibrium is obtained for off-net prices $\left(p^{*}, r^{*}\right)$ and achieves full efficiency. Any other equilibrium exhibits inefficiently low call volume. Efficiency can only be obtained when $m=\bar{m}$.

[ii] The profit maximizing equilibrium is obtained for off-net prices $\left(\hat{p}^{\pi}, \hat{r}^{\pi}\right)$ determined by

$$
\hat{r}^{\pi}=\beta \hat{p}^{\pi} \text { and } \hat{p}^{\pi}=\arg \max _{p}((1+\beta) p-c) q(p) .
$$

Maximum profit can be obtained when $m=m^{C}\left(p^{\pi}, r^{\pi}\right)>\bar{m}$ and by $m=m^{R}\left(p^{\pi}, r^{\pi}\right)<\bar{m}$ (if $\left.m^{R}\left(p^{\pi}, r^{\pi}\right) \geq-c_{T}\right)$.

Duality. It is not a coincidence that the maximal profit can possibly be obtained by two different equilibria. It is obvious that any $(\hat{p}, \hat{r}) \in E^{R} \cap E^{C} \backslash\left\{\left(p^{*}, r^{*}\right)\right\}$ can be obtained both in an equilibrium with call volume determined by the caller (namely when $m=m^{C}(\hat{p}, \hat{r})$ ) and in an equilibrium with call volume determined by the receiver (namely when $m=m^{R}(\hat{p}, \hat{r})$ ). However, the idea that what can be obtained in an equilibrium in which the receiver determines volume can also be obtained in an equilibrium in which the caller determines volume, and vice versa, holds more generally. To be more precise, let us say that $e^{\prime}=\left(\hat{p}^{\prime}, \hat{r}^{\prime}\right) \in E^{C}$ is the dual of $e=(\hat{p}, \hat{r}) \in E^{R}$ if call volume and profit in $e$ are the same as call volume and profit in $e^{\prime}$. Dual equilibria are equally efficient and yield the same profit, and thus also yield exactly the same consumer surplus. The only differences lie in the identity of the person who determines the volume of the call and in the required termination rate to support these prices as an equilibrium. It is easy to construct for each $e \in E^{R}$ the unique candidate dual, $e^{\prime}$. Namely, to have equal call volume it must be that $\hat{p}^{\prime}=\hat{r} / \beta$. To have moreover the same profit, it must be that $\hat{r}^{\prime}=\hat{p}+\hat{r}-\hat{p}^{\prime}$. Of course, in general the constructed $e^{\prime}$ may not lie within $E^{C}$, as it may not satisfy some of the linear constraints that characterize $E^{R}$. For example, it is straightforward to show that $\hat{r}^{\prime} \geq 0$ requires that $\hat{r} / \hat{p} \leq \beta /(1-\beta)$. Also, the condition $\beta \hat{p}^{\prime} \geq-m^{C}\left(\hat{p}^{\prime}, \hat{r}^{\prime}\right)$ is equivalent to $\hat{r} \geq \beta\left[c+m^{R}(\hat{p}, \hat{r})\right]$.

Proposition 7 (Duality property) There exist subsets $\tilde{E}^{R} \subset E^{R}$ and $\tilde{E}^{C} \subset E^{C}$ such that for any $e \in \tilde{E}^{R}$ there exists its dual $e^{\prime} \in \tilde{E}^{C}$, where call volume, profit and consumer surplus are the same. Similarly, for any $e^{\prime} \in \tilde{E}^{C}$ there exists its dual $e \in \tilde{E}^{R}$, where call volume, profit and consumer surplus are the same. Moreover, equilibria outside $\tilde{E}^{R}$ and $\tilde{E}^{C}$ do not have a dual equilibrium.

Figure 2 shows the construction of the dual equilibrium. The dark shaded areas indicate the subsets of $E^{R}$ and $E^{C}$ that have dual equilibria. The duality property illustrates the idea that there is no fundamental difference between origination and termination or between call 
and reception charges. Only the restriction to non-negative call, reception and termination prices limits the duality property to a subset of equilibria. Of course, negative prices may lead firms or consumers to engage in arbitrage opportunities: For example, a sufficiently negative termination charge (or positive origination charge) may give firms perverse incentives to place a huge amount of off-net calls to collect "origination rents".

\section{Equilibrium selection}

We have shown that a multiplicity of symmetric equilibria exists. This means that networks face a huge coordination problem. Without addressing this coordination problem it is impossible to do policy analysis and recommend a particular termination mark-up. Namely, the socially optimal termination mark-up will depend on which of the equilibria networks will play. We discuss four possible equilibrium selection hypotheses. First, we consider using the CPP regime as an equilibrium selection device or focal point where the equilibrium with zero reception charges is used. This corresponds to current European practice. Second, we consider the equilibrium where call and reception charges are equal. This selection criterion is motivated by the observation that in countries where a RPP regime is in place, call and reception charges are usually the same. We will denote this equilibrium by $\mathrm{RPP}^{*}$. As we shall see, the CPP and RPP* equilibria do not exist for all values of the termination charge. Nevertheless, these focal points are interesting from a real world perspective, and give us the opportunity to compare the efficiency and profitability of the European and US telecommunication markets. We consider two more equilibrium selection criteria. By introducing vanishing noise (as first introduced by JLT) in the marginal utilities of receivers one can ensure that both callers and receivers sometimes determine the length of the call and this always picks a unique equilibrium. Finally, we consider the benchmark case where firms coordinate on the most profitable equilibrium.

In order to avoid potential problems of equilibrium existence, we will assume from now on that $(n-1) \beta>1$ and that the product differentiation parameter $\mu$ is sufficiently large. These conditions are sufficient for the existence of the equilibria characterized in Proposition 2. The first condition is also a necessary condition for equilibria to exist in which the receiver determines the volume (see Proposition 4). 


\subsection{CPP}

If firms play an equilibrium in which receiving calls is free of charge, they must play the equilibrium $\left(p, r, \hat{p}^{*}, \hat{r}^{*}, F^{* *}\right)$ where

$$
r=0, \quad p=\frac{c}{1+\beta}, \quad \hat{r}^{*}=0, \quad \hat{p}^{*}=\frac{(n-1)(c+m)}{n-1-\beta},
$$

and

$$
F^{* *}=f+\frac{n \mu}{n-1}-\frac{n-2}{n}\left(\hat{p}^{*}-c\right) q\left(\hat{p}^{*}\right)+\frac{1}{n} \frac{\beta c}{1+\beta} q\left(\frac{c}{1+\beta}\right) .
$$

Note that on-net reception price must now be equal to zero. Observe that in the fixed fee we added the payment that in the equilibrium described in Proposition 2 was collected through positive on-net reception charges. Equilibrium profit is still given by (8) (with $\left.\hat{r}^{*}=0\right)$.

Note that when $n>2$, the off-net call price does not converge to infinity as the call externality $\beta$ tends to one. In this sense the equilibrium does not exhibit asymptotic connectivity breakdown. This contrasts with the observations by JLT and López (2011) about asymptotic connectivity breakdown in duopolistic markets.

Recall from Proposition 2 that a necessary condition for this equilibrium to exist is that $\beta \hat{p}^{*} \geq-m$, which is equivalent to $m \geq \underline{m}^{C P P}$, where

$$
\underline{m}^{C P P}=\frac{-\beta c}{\beta+1-\frac{\beta}{n-1}} .
$$

For lower termination mark-ups any equilibrium must have positive charges for reception.

The termination mark-up that maximizes firms' profits is the one that maximizes $\left(\hat{p}^{*}-\right.$ c) $q\left(\hat{p}^{*}\right)$. That is, firms prefer termination mark-up that yields off-net price equal to monopoly price $p^{M}$. Hence, the termination mark-up that maximizes firms' profits equals

$$
m^{\pi}=\frac{n-1-\beta}{n-1} p^{M}-c .
$$

Observe that $m^{\pi}>\underline{m}^{C P P}$ so that this profit maximizing equilibrium indeed exists.

Note that for industries with at least three firms the profit maximizing termination markup will be positive whenever call demand is relatively inelastic, in which case the monopoly price is quite high. Only for extremely elastic call demand, the monopoly price will be close to cost and the profit maximizing termination mark-up will be negative. In case of iso-elastic call demand, $q(p)=p^{-\eta}$, the monopoly price equals $p^{M}=\eta c /(\eta-1)$ so that $m^{\pi}>0$ if and only if $\eta<(n-1) / \beta$. 
The socially optimal termination mark-up would be the one that achieves the efficient call volume, i.e. such that $\hat{p}^{*}=c /(1+\beta)$. Hence, the optimal termination mark-up would be

$$
m^{W}=\left(\frac{-\beta c}{1+\beta}\right)\left(\frac{n}{n-1}\right)<0
$$

However, it is easily established that $m^{W}<\underline{m}^{C P P}$. This means that regulating termination charges at efficient levels is incompatible with a CPP equilibrium, if firms are free to charge for reception. ${ }^{17}$ This was of course already clear from Proposition 6 , where we saw that efficiency can only be obtained with off-net prices equal to $\left(p^{*}, r^{*}\right)$. Were regulators to impose $m^{W}$ in the hope to achieve efficiency, operators would be forced to play an equilibrium in which consumers are charged a positive price for receiving calls. Alternatively, regulators could impose the lowest termination mark-up compatible with CPP (i.e., $\underline{m}^{C P P}$ ), and accept some inefficiency. ${ }^{18}$

\section{$4.2 \mathrm{RPP}^{*}$}

From Proposition 4 we know that an equilibrium with equal charge for placing and receiving calls can only exist when the termination mark-up is sufficiently low. In particular, the termination mark-up must be negative. Such an equilibrium must have

$$
\hat{p}=\hat{r}=\frac{\beta(n-1) m}{1-n \beta}
$$

The necessary condition $\hat{r} \geq \beta(c+m)$ is satisfied if and only if $m \leq \bar{m}^{R P P}$, where

$$
\bar{m}^{R P P}=\frac{c(1-n \beta)}{n-2+n \beta} .
$$

The social welfare maximizing termination mark-up would be the one that makes $\hat{r}$ equal to $\beta c /(\beta+1)$, so that $m_{R P P}^{W}=c(1-n \beta) /((1+\beta)(n-1))$. However, $m_{R P P}^{W}>$ $\bar{m}^{R P P}$. Regulating termination charges at efficient levels is thus incompatible with an $\mathrm{RPP}^{*}$ equilibrium. As in the case of CPP, this was already clear from Proposition 6 where we saw that the only efficient equilibrium off-net prices satisfy $r^{*}=\beta p^{*}<p^{*}$. Alternatively, regulators could try to impose the highest termination mark-up compatible with $\mathrm{RPP}^{*}$ (i.e., $\bar{m}^{R P P}$ ), and accept some inefficiency. However, even this may be problematic because it may be in the interest of firms to agree on lower termination rates, such as Bill and Keep, which

\footnotetext{
${ }^{17}$ If firms are prevented from the option to charge reception (perhaps by law), then efficiency can be achieved in a CPP equilibrium (see Berger (2005)).

${ }^{18}$ If $\underline{m}^{C P P}<-c_{T}$, the best regulators can do is to impose Bill and Keep.
} 


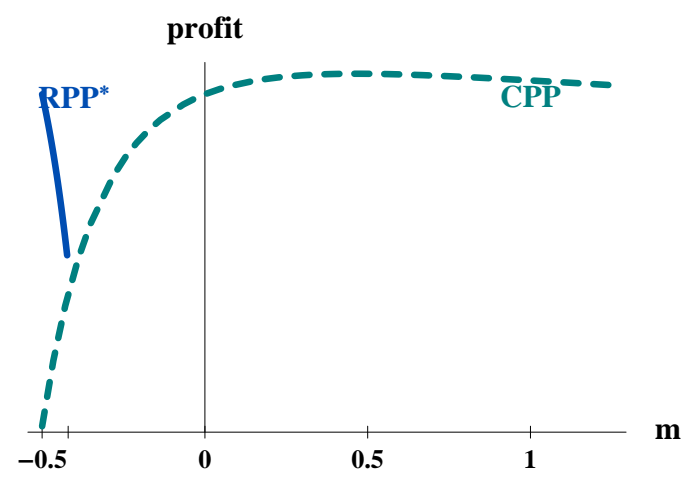

(a) $q(p)=p^{-2}$ and $\beta=0.8$

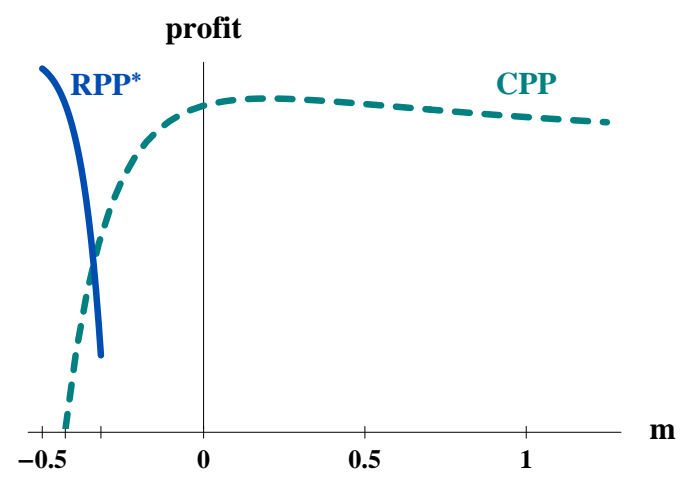

(b) $q(p)=p^{-3}$ and $\beta=0.6$

Figure 3: Profit for $n=4, c_{O}=c_{T}=0.5$ in CPP and $\mathrm{RPP}^{*}$ equilibrium.

may lead to higher profits and lower welfare. This is certainly the case when call demand is iso-elastic. With iso-elastic call demand $q(p)=p^{-\eta}$, the (unconstrained) profit maximizing termination mark-up would equal $m^{\pi}=-c \eta(n \beta-1) /(2 \beta(\eta-1)(n-1))<-p^{M} / 2$, so that Bill and Keep is optimal if negative termination charges are ruled out and $c_{T} \leq c / 2$. Hence, if regulators would set $\bar{m}^{R P P}$ as an upper level on the termination mark-up, firms would voluntarily agree on a Bill and Keep regime. This would lead to even larger efficiency losses because lower termination charges (that is, stronger negative termination mark-ups) lead to higher usage prices and thus to lower usage.

Comparison between CPP and RPP*. Let us illustrate some of the issues at hand by means of two numerical examples. We assume $n=4$ and $c_{O}=c_{T}=0.5$. In case (a) we further assume that $q(p)=p^{-2}$ and $\beta=0.8$, while in case $(b)$ we assume that $q(p)=p^{-3}$ and $\beta=0.6$. Figure 3 shows the equilibrium profit as a function of termination mark-up $m$ for the CPP and RPP* equilibria. Note that in case $(a)$ the CPP equilibrium exists for any $m \geq-0.5$ (because $\underline{m}^{C P P}=-0.52$ ), while the RPP* equilibrium exists only for $m \leq-0.42$. In case $(b)$ the $\mathrm{CPP}$ equilibrium exists for $m \geq-0.43$ while the RPP* equilibrium exists for $m \leq-0.32$. One observes that equilibrium profit in the CPP equilibrium decreases as termination mark-up is lowered. At some point firms would prefer to switch to the RPP* equilibrium. As the termination mark-up is lowered all the way to Bill and Keep, profit in the RPP* equilibrium increases. In fact, the profit under Bill and Keep can even be higher than the maximum profit in any CPP equilibrium as is shown in Figure 3(b).

In order to illustrate how efficiency is affected, we plot call volume in Figure 4. The top level indicates the efficient call volume, which cannot be achieved by any termination markup for either type of equilibrium. The lower the termination mark-up, the more efficient is the CPP equilibrium and the less efficient is the RPP* equilibrium. However, depending on 


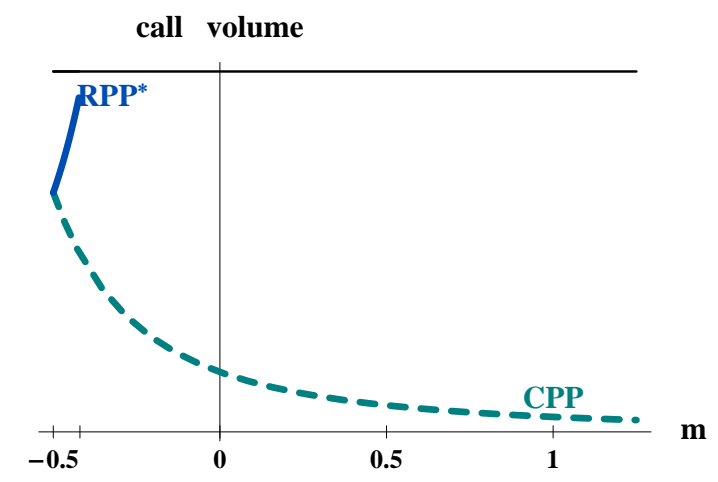

(a) $q(p)=p^{-2}$ and $\beta=0.8$

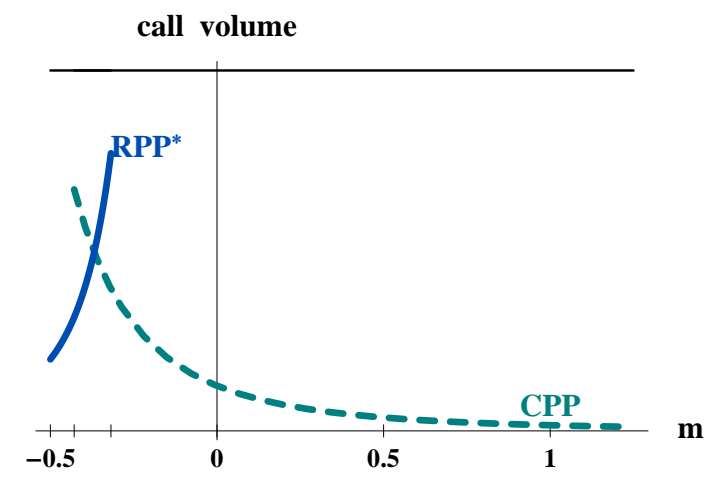

(b) $q(p)=p^{-3}$ and $\beta=0.6$

Figure 4: Call volume for $n=4, c_{O}=c_{T}=0.5$ in CPP and RPP* equilibrium.

the level of the termination mark-up either CPP or RPP* may be better. In particular, in case (a) CPP is outperformed by $\mathrm{RPP}^{*}$ in terms of total welfare, but in case $(b)$, there are termination mark-ups where CPP outperforms RPP*. Another striking feature is that under the RPP* equilibrium firms would prefer to use Bill and Keep but regulators would actually prefer higher termination rates. That is, firms voluntarily agreeing on Bill and Keep need not be in the interest of social or consumer welfare.

An eye catching comparison is the one between the US scenario with Bill and Keep $\left(m=-c_{T}\right)$ and $\mathrm{RPP}^{*}$ (equal prices for placing and receiving calls), and the (future) situation in Europe with termination regulated at cost $(m=0)$ and CPP. Let us assume again that $c_{O}=c_{T}=c / 2$. We will now compare both scenarios in terms of producer, consumer and total surplus.

In the US scenario, off-net call and reception price are then equal to $\hat{p}^{\mathrm{US}}=\hat{r}^{\mathrm{US}}=$ $\beta(n-1) c /(2(n \beta-1))$, so that call volume equals $q \mathrm{US}=q\left(\hat{r}^{\mathrm{US}} / \beta\right)$. Under the European scenario off-net call price equals $\hat{p}^{\mathrm{EUR}}=(n-1) c /(n-1-\beta)$ and off-net call volume is equal to $q^{\mathrm{EUR}}=q\left(\hat{p}^{\mathrm{EUR}}\right)$. Call volume would thus be higher (and more efficient) in the European scenario if and only if $\beta<(n+1) /(2 n+1)$. On the other hand, the margin earned on each minute of call in the European scenario (i.e., $\hat{p}^{\mathrm{EUR}}-c$ ) will be higher than the one in the US scenario (i.e., $2 \hat{p}^{\mathrm{US}}-c$ ) if and only if $\beta>\bar{\beta}=(\sqrt{5}-1) / 2$. Because $(n+1) /(2 n+1) \leq 4 / 7<\bar{\beta}$ for all $n \geq 3$, it follows that when the two scenarios are equally efficient, the European producers earn less profits than their US counterparts. This then also implies that consumer surplus must be strictly higher under the European scenario when both scenarios are equally efficient (in terms of total surplus). Another consequence is that for no value of $\beta$ it can be true that both producer and consumer surplus are the same in both scenarios. 
From the deliberations above we have that for intermediate values of $\beta \in[(n+1) /(2 n+$ $1), \bar{\beta}]$, European producers earn less profits. However, both for lower and higher values European operators may earn higher profits than their US counterparts. On the one hand, as $\beta$ approaches 1 the profit margin for US producers converges to zero, while the one for European producers is bounded away from zero. Hence, if call demand is bounded from above, European producers earn higher profits for high values of $\beta$. On the other hand, when $\beta$ approaches the lower bound (for existence of $\operatorname{RPP}^{*}$ equilibria) $1 /(n-1)$, European producers will earn more if call demand is very elastic, despite the lower margin earned on calls, because of the much higher quantity sold.

We summarize our findings in the following proposition. An illustration of this proposition is given in Figure 5. For the case of call demand with constant elasticity $\eta$ and call externality $\beta$, different regions in the $(\eta, \beta)$-space are identified where, respectively, producer, consumer or total surplus are higher under the European scenario (indicated by the sign ' + ').

Proposition 8 Let $n \geq 3$ and call demand be bounded from above and sufficiently elastic over the relevant range of prices. Then there exist cut-off values $1 /(n-1)<\beta_{1}<\beta_{2}=$ $(n+1) /(2 n+1)<\beta_{3}<\beta_{4}<1$ such that

[i] Producer surplus is higher under the European scenario than under the US scenario when $\beta<\beta_{1}$ and when $\beta>\beta_{4}$.

[ii] Consumer surplus is higher under the European scenario than under the US scenario when $\beta<\beta_{3}$.

[iii] Total surplus is higher under the European scenario than under the US scenario when $\beta<\beta_{2}$.

\subsection{Noisy receiver utility}

Here we follow the approach first introduced in JLT (2004) and later also applied by Cambini and Valletti (2008), López (2011), and Hoernig (2012). The idea is that the marginal utility a receiver obtains from a call is subject to some noise, so that, whatever the call and reception charges are, there is a positive probability that the caller hangs up first and there is a positive probability that the receiver hangs up first. This will imply that both call and reception charges matter so that they can be uniquely determined. By considering the limiting case where the noise vanishes (in a regular way) this method selects a unique equilibrium among the set of equilibria in the game without noise.

Proposition 9 The criterion of vanishing noise selects the following equilibrium, depending on the termination mark-up $m$ : 




Figure 5: Producer, consumer and total surplus comparison between European and US scenario. (A '+' sign indicates that the relevant welfare measure is higher under the European scenario.)

[i] If $m \geq 0$, the equilibrium selected has $\hat{r}=0$ and $\hat{p}=(n-1)(c+m) /(n-1-\beta)$. Reception (off-net) is not charged and the caller determines the call volume.

[ii] If $\bar{m} \leq m \leq 0$, the equilibrium selected has $\hat{r}=-m$ and $\hat{p}=((n-1) c+n m) /(n-1-\beta)$. Reception (off-net) is charged but the caller determines the call volume.

[iii] If $-c_{T} \leq m \leq \bar{m}$, the equilibrium selected has $\hat{p}=c+m$ and $\hat{r}=-\beta(c+n m) /((n-$ 1) $\beta-1)$. The receiver determines call volume.

It is easily verified that call volume in the selected equilibrium is increasing in $m$ for $m<\bar{m}$ and decreasing in $m$ for $m>\bar{m}$, and that the efficient call volume is obtained when $m_{\text {noise }}^{W}=\bar{m}$. Note that this socially efficient termination mark-up is not optimal for firm's profits. One can verify that $\hat{p}+\hat{r}$ is increasing in $m$ at $m>\bar{m}$, and that at $m=\bar{m}, \hat{p}+\hat{r}=p^{*}+r^{*}=c$. From the expression of equilibrium profit in Proposition 2 it follows that increasing $m$ above $\bar{m}$ will increase each firm's profit. It is not straightforward to determine the profit-maximizing termination mark-up for general call demand functions. Depending on the elasticity of call demand and the strength of the call externality, the 


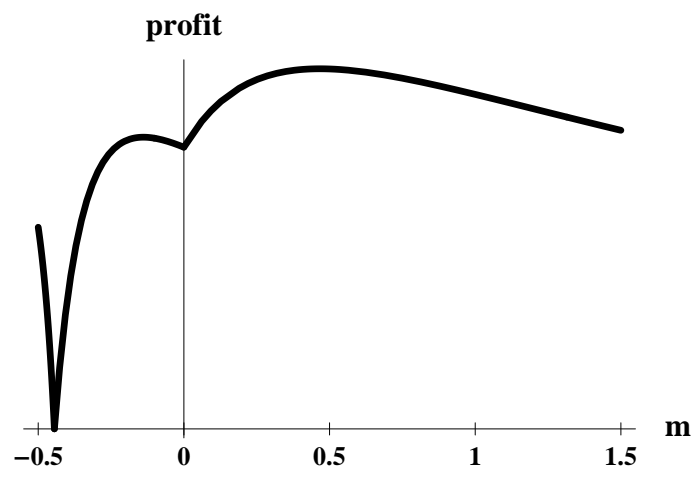

(a) $q(p)=p^{-2}$ and $\beta=0.8$



(b) $q(p)=p^{-3}$ and $\beta=0.6$

Figure 6: Profit for $n=4, c_{O}=c_{T}=0.5$ in equilibrium selected by vanishing noise.

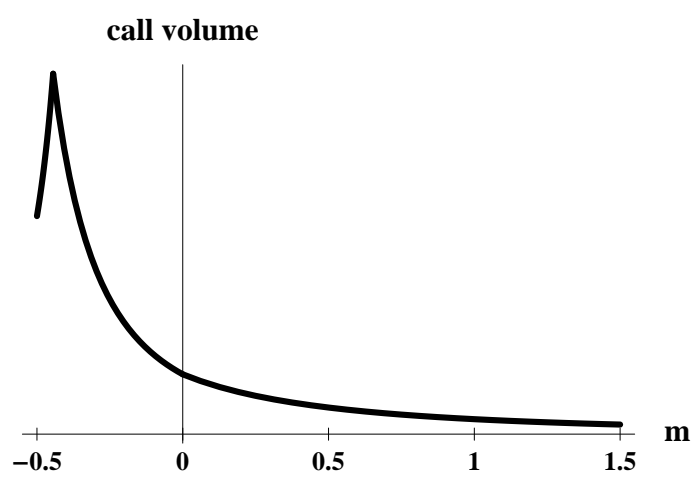

(a) $q(p)=p^{-2}$ and $\beta=0.8$

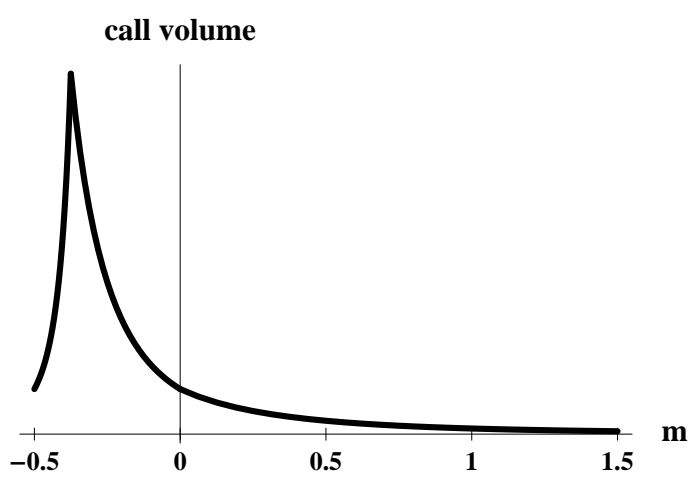

(b) $q(p)=p^{-3}$ and $\beta=0.6$

Figure 7: Call volume for $n=4, c_{O}=c_{T}=0.5$ in equilibrium selected by vanishing noise.

optimal termination mark-up for firms can be strictly positive (leading to a CPP outcome) or can be negative (leading to an RPP outcome). For example, consider a case with $n=4$ firms and $c_{O}=c_{T}=0.5$. When $q(p)=p^{-2}$ and $\beta=0.8$, the profit maximizing termination mark-up is about 0.5. (See Figure 6(a).) When instead $q(p)=p^{-3}$ and $\beta=0.6$ the optimal termination mark-up is about $-0.18>\bar{m}=-0.375 .^{19}$ (See Figure 6(b).) Call volume is always efficient at $\bar{m}$. (See Figures $7(\mathrm{a})$ and $7(\mathrm{~b})$.)

\subsection{Coordination}

Let us imagine that for any given termination charge firms coordinate on the equilibrium with the highest (joint) profit. The profit maximizing equilibrium is the one where $\hat{r}=\beta \hat{p}$. This is so because it is the equilibrium with the highest call volume and the largest non-

\footnotetext{
${ }^{19}$ In this case a termination mark-up of $m=-0.44$ also maximizes firm's profit. This is due to the duality between equilibria with caller and receiver determined volume explained in Proposition 7 .
} 


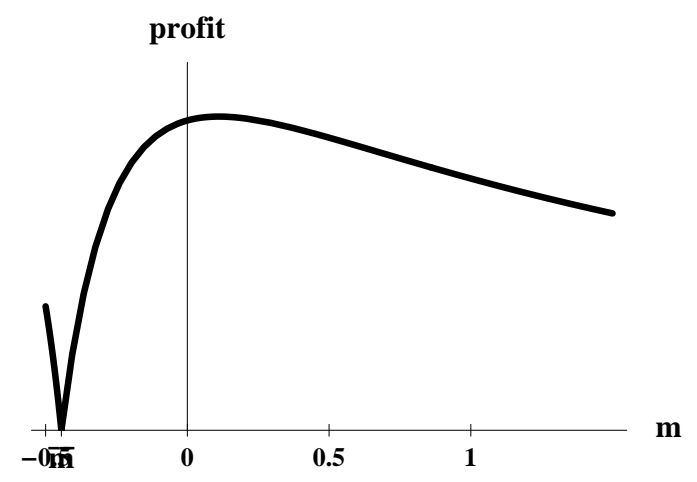

(a) $q(p)=p^{-2}$ and $\beta=0.8$

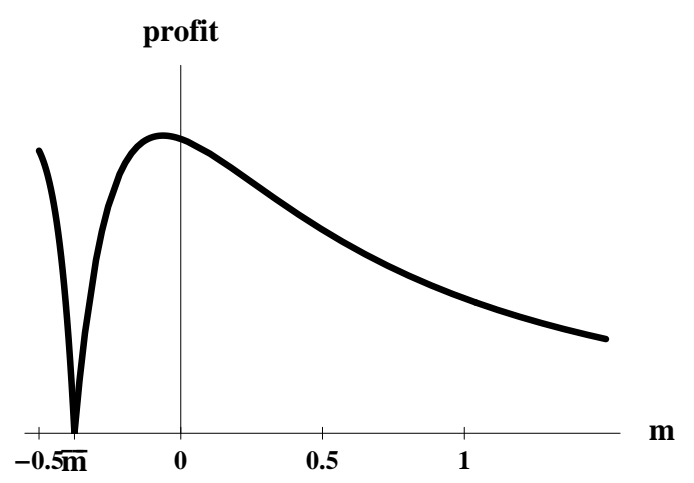

(b) $q(p)=p^{-3}$ and $\beta=0.6$

Figure 8: Profit for $n=4, c_{O}=c_{T}=0.5$ in equilibrium selected by coordination.

negative profit margin $\hat{p}+\hat{r}-c$. For $m \geq \bar{m}$, the equilibrium has $\hat{r}=\beta \hat{p}=\beta(c+m)$, so that $\hat{p}+\hat{r}-c=(1+\beta)(c+m)-c \geq 0$. For $m \leq \bar{m}$, the equilibrium has $\hat{r}=\beta \hat{p}=-m$, so that $\hat{p}+\hat{r}-c=-m(1+\beta) / \beta-c \geq 0$. (See Figure 1.)

The termination mark-up that maximizes efficiency is the one that yields call volume $q(c /(1+\beta))$. It is straightforward to see that $m_{\text {coor }}^{W}=\bar{m}$. The profit maximizing termination mark-up above $\bar{m}$ is the one that maximizes $((1+\beta)(c+m)-c) q(c+m)$. (This will yield the maximal profit over all equilibria, see Proposition 6.) In the case of iso-elastic call demand $q(p)=p^{-\eta}$, the optimal termination mark-up is such that total price $(\hat{p}+\hat{r})$ equals monopoly price $p^{M}$. Call volume will be larger than under monopoly, because it is given by $q\left(p^{M} /(1+\beta)\right)$. To be precise, $m^{\pi}=p^{M} /(1+\beta)-c$. Because of duality, the same optimal profit could, in principle, also be obtained with a termination mark-up below $\bar{m}$, namely with $m^{W}=-\beta p^{M} /(1+\beta) .{ }^{20}$ However, this would often require a negative termination charge. In case $(a)$, the profit-maximizing termination mark-up is equal to $1 / 9$, in case $(b)$ it is equal to $-1 / 16$. (See Figure 8). So in the first case, if firms could decide on termination mark-up and equilibrium, they would choose a positive mark-up but still use a RPP business model. If regulators would try to impose $\bar{m}$ as an upper level on the termination mark-up, firms would voluntarily agree on Bill and Keep. As Figure 9 shows, such a jump to Bill and Keep would reduce efficiency compared to the first best situation, especially in case $(b)$. Bill and Keep is only somewhat better than cost-based termination charges. More generally, Bill and Keep yields call volume $q\left(c_{T} / \beta\right)$ while a cost-based termination charge yields call volume $q(c)$. Hence, Bill and Keep is more efficient than cost-based termination when firms coordinate on the profit maximizing equilibrium if and only if $\beta>c_{T} / c$.

\footnotetext{
${ }^{20}$ This would again yield total price equal to monopoly price and call volume as before.
} 


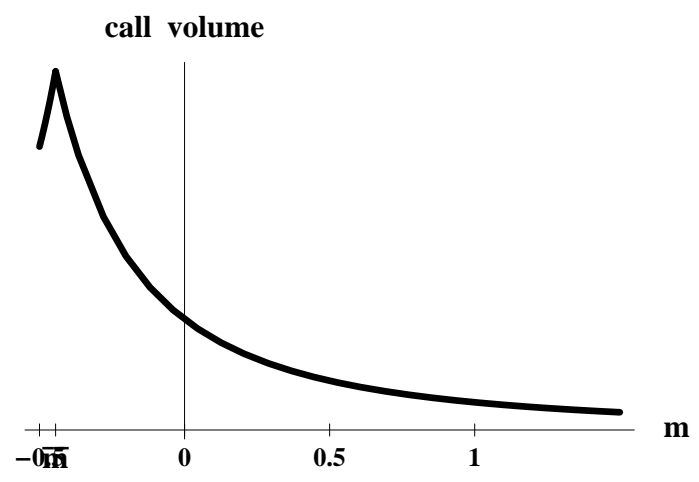

(a) $q(p)=p^{-2}$ and $\beta=0.8$

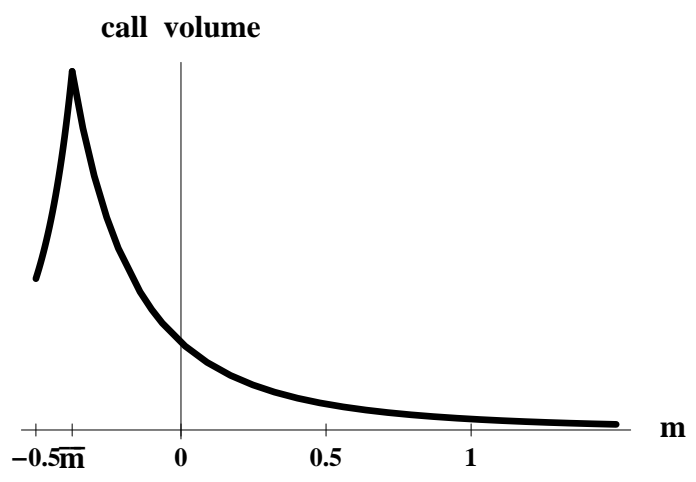

(b) $q(p)=p^{-3}$ and $\beta=0.6$

Figure 9: Call volume for $n=4, c_{O}=c_{T}=0.5$ in equilibrium selected by coordination.

\section{The role of expectations}

We have assumed throughout that consumers form passive expectations about network sizes. That is, consumers form expectations before firms set prices and do not change them once they observe the prices set by all firms. This is in contrast to the previous literature on termination (with the exception of Hurkens and López (2014)) that assumes consumers form responsive expectations, so that expectations are perfectly adjusted when prices are changed. The type of expectations does not affect the equilibrium off-net call and reception prices. The strategic marginal cost pricing principle holds with responsive and passive expectations because in both cases one uses the standard trick to maximize profit holding market shares constant at $1 / n$ (so that responsive and passive expectations coincide). However, the type of expectations is crucial for determining fixed fees and profits. When off-net traffic provides less net consumer surplus than on-net traffic (per call) then consumers prefer to belong to the larger network. Under the assumption of responsive expectations consumers realize that a firm that unilaterally lowers its fixed fee will become the larger network. Hence, some consumers switch to that network not just because of the lower fixed fee but also because they foresee that they will place and receive more on-net calls in comparison to other networks. Under responsive expectations competition is thus fiercer than under passive expectations whenever off-net traffic provides less surplus to consumers than on-net traffic.

This was already pointed out by Hurkens and López (2014) in case reception is exogenously determined to be free of charge. It must thus also hold here when firms play the CPP equilibrium. For example, if firms play the equilibrium selected by vanishing noise and $m>0$, then fixed fees and profits are lower under responsive expectations than under passive expectations. Even stronger, equilibrium profit increases under passive expectations and decreases under responsive expectations when $m$ is raised above 0. Given the observed 




Figure 10: Profit for $n=4, c_{O}=c_{T}=0.5, q(p)=p^{-2}$ and $\beta=0.8$ in equilibrium selected by vanishing noise under passive (upper curve) and responsive (lower curve) expectations.

opposition by firms against lowering termination charges in European countries, the predictions obtained under passive expectations seem more plausible than those obtained under responsive expectations.

In order to understand better the role of expectations when reception is charged, we calculate fixed fees and equilibrium profit for the case of responsive expectations for the equilibrium robust to vanishing noise. ${ }^{21}$

Proposition 10 [i] Assuming responsive expectations and vanishing noise, the symmetric equilibrium is $\left(p^{*}, r^{*}, \hat{p}, \hat{r}, \tilde{F}\right)$ where $\hat{p}$ and $\hat{r}$ are as in Proposition 9. Denoting consumer surplus from on-net calls by

$$
v^{*}=(1+\beta) u\left(q\left(p^{*}\right)\right)-c q\left(p^{*}\right)
$$

and consumer surplus from off-net calls by

$$
\hat{v}=(1+\beta) U(\hat{p}, \hat{r})-(\hat{p}+\hat{r}) D(\hat{p}, \hat{r}),
$$

${ }^{21}$ JLT and Hoernig (2012) seem only interested in efficiency and connectivity breakdown, as they do not calculate fixed fees nor profits. Cambini and Valletti (2008) do examine profit but restrict attention to equilibria in which the caller determines volume (most of the time). They show that as the termination charge is lowered towards the efficient level, equilibrium profits go up. Because for termination charges below the efficient level no equilibrium exists in which the caller determines volume and no connectivity breakdown occurs, they conclude that breakdown must occur for inefficiently low termination charges. They then verify that an equilibrium with connectivity breakdown yields lower profit than the equilibrium without breakdown and thus conclude that free commercial negotiations lead firms to set efficient charges. In contrast, we will consider that when termination charge is set below the efficient level, firms play the equilibrium in which receivers determine volume and still show that under the assumption of responsive expectations firms will voluntarily agree on the efficient termination charge. 
fixed fee equals

$$
\widetilde{F}=f+\frac{n \mu}{n-1}-\frac{v^{*}-\hat{v}}{n-1}-\frac{n-2}{n}(\hat{p}+\hat{r}-c) D(\hat{p}, \hat{r})
$$

and equilibrium profit equals

$$
\widetilde{\pi}=\frac{\mu}{n-1}-\frac{v^{*}-\hat{v}}{n(n-1)}+\frac{1}{n^{2}}(\hat{p}+\hat{r}-c) D(\hat{p}, \hat{r}) .
$$

[ii] Maximal profit is obtained for $m=\bar{m}$, so that $\hat{p}=p^{*}$ and $\hat{r}=r^{*}$. That is, free negotiation between firms about a reciprocal termination rate leads to the efficient outcome.

One sees immediately that the difference between equilibrium profits under passive and responsive expectations is captured by the term $\left(v^{*}-\hat{v}\right) /(n(n-1))$. Raising off-net surplus increases fixed fee and profit. It should thus not come as a surprise that firms prefer to agree on the efficient termination rate under responsive expectations. Figure 10 compares profits under passive and responsive expectations for the equilibrium selected by vanishing noise. ${ }^{22}$ Observe that the profits under passive and responsive expectations agree exactly when the efficient termination charge is set. This is so because then off-net prices are efficient and thus equal to the on-net prices. This implies that then the tariff-mediated network effect disappears and the type of expectations is thus irrelevant. As the termination charge is moved away from the efficient one, the profit under responsive expectations decreases while under passive expectations it increases.

\section{Concluding remarks}

In this paper we revisited the analysis of the effect of termination charges on competition and welfare when receivers obtain utility from incoming calls and network operators can charge call reception. Compared to earlier literature on this topic we assume that consumers form passive expectations about network sizes. In addition, we extended the traditional duopoly model to the case of competition among multiple networks, and allow both callers and receivers to hang up. We derived the full set of equilibria for any termination charge and analyzed both efficiency and profitability of the industry under different termination charges and equilibrium selection hypotheses. We showed that the possibility of connectivity breakdown becomes unimportant and a unique efficient equilibrium exists when there are at least three firms (and call externality is not too low).

\footnotetext{
${ }^{22}$ Note that the profit under passive expectations for this case was already drawn in Figure 6(a). Profits have been rescaled somewhat to better illustrate the difference between passive and responsive expectations.
} 
We showed that efficiency requires that $\hat{p}=p^{*}=\lambda c$ and $\hat{r}=r^{*}=(1-\lambda) c$, where $\lambda=1 /(1+\beta)$ denotes the share of the total value of a call enjoyed by the caller. That is, caller and receiver must share the total cost of a call in proportion to the benefit they enjoy from it. ${ }^{23}$ This in turn can only occur when the termination charge equals $a^{*}=c_{T}-\beta c /(1+\beta)$. Note that with termination charge $a^{*}$ the perceived marginal cost of originating an off-net call equals $c_{O}+a^{*}=\lambda c$ and the perceived marginal cost of terminating an off-net call equals $c_{T}-a^{*}=(1-\lambda) c$. Hence, in the efficient equilibrium the total cost of a call must also be shared by the two operators in the same proportion as their subscribers benefit from it. This cost-sharing rule does not depend on how total cost is actually composed. Of course, the actual termination charge does depend on the composition. The originating operator should pay the terminating operator a fraction $a^{*} / c_{T}$ of the termination cost. Assuming that $c_{O}=c_{T}=c / 2$, this fraction equals $a^{*} / c_{T}=(1-\beta) /(1+\beta)=2 \lambda-1$, and decreases from 1 to 0 when $\beta$ increases from 0 to 1 : If caller and receiver share the value of a call equally $(\beta=1)$, Bill and Keep $\left(a^{*}=0\right)$ is optimal. Hence, we obtain an answer to our question of who and how much should be paid for interconnection. Our answer is reminiscent to the one provided by DeGraba (2003). DeGraba (2003) shows that if firms set prices equal to perceived marginal cost then efficiency obtains when termination charge is set to $a^{*}$. We have shown, however, that the equilibrium price that determines call volume is equal to strategic marginal cost, which in general is different from perceived marginal cost. Even when termination is fixed at $a^{*}$, firms may end up playing a different, and thus inefficient, equilibrium. We also showed that this coordination problem is resolved if one is willing to assume that firms play, for any given termination charge, the equilibrium that yields the highest industry profit, or the equilibrium robust to vanishing noise (as JLT, Cambini and Valletti (2008) and Hoernig (2012) do).

Efficiency is thus feasible in theory, but probably hard to achieve in practice for several reasons. First, the assumption that firms play the equilibrium robust to vanishing noise is rather strong and ad hoc. Firms may very well play a different equilibrium. Recall that for each termination charge there exists a continuum of equilibria. For example, if firms play the CPP equilibrium (as they seem to do in Europe) or the RPP* equilibrium (as they seem to do in the US), full efficiency is impossible. Constrained efficiency (that is, maximal efficiency given the type of equilibrium played) requires termination rates different from $a^{*}$. For example, assuming again that $c_{T}=c / 2$, if CPP is played the constrained optimal termination charge is lower than $a^{*}$ (and equal to zero for high values of $\beta$ ). If, on the other

\footnotetext{
${ }^{23}$ DeGraba (2003) showed that such prices yield efficient consumption, but noted that efficiency also obtains when only one party faces the efficient price while the other party faces a price below the efficient one. We showed that such alternative combination of prices are never part of an equilibrium.
} 
hand, RPP* is played, the constrained optimal termination charge is higher than $a^{*}$. This suggests that termination rates in Europe should perhaps be lowered below cost and that Bill and Keep regimes in the US should not be overrated from an efficiency point of view. Second, firms may have incentives to agree on termination charges below the one set by the regulator. This may lead to higher profits but lower total and consumer welfare. This is for example the case when firms play the RPP* equilibrium, the equilibrium robust to vanishing noise or the one preferred by firms (but not when the CPP equilibrium is played). This is a serious problem if regulators can only set a ceiling on termination rates but cannot prevent firms from agreeing to lower ones. It also shows that letting firms negotiate reciprocal termination charges may lead to inefficient Bill and Keep regimes. Third, the regulator may simply lack knowledge about the strength of call externalities and is thus unable to determine the optimal termination charge.

Given all these problems to achieve first-best efficiency, we have provided a comparison between the European and US scenarios. The CPP regime in Europe together with costbased termination (as recommended by the EC) may actually outperform the RPP* regime in the US with voluntary Bill and Keep arrangements in terms of efficiency (and also profitability). In particular, the European scenario is more efficient as long as $\beta<(n+1) /(2 n+1)$. Of course, lowering termination below cost in Europe leads to a wider range of call externality parameters for which the resulting outcome is more efficient than the US scenario. On the other hand, if $\beta$ is very close to one, then $\mathrm{RPP}^{*}$ with Bill and Keep is better and in fact close to first-best.

It would be extremely important to have a better idea of how strong call externalities actually are. This is presumably an empirical matter, but the current paper may also prove to be useful in this direction. Namely, our theoretical model (employing passive expectations) makes predictions that are in line with real world observations about telecommunication wholesale and retail prices in both CPP and RPP countries $^{24}$. We believe therefore that our model can be used to empirically estimate the strength of the call externality and give reliable results. This would then be very useful for the discussion about the pros and cons of RPP and CPP regimes and for future policy about regulation of termination rates. ${ }^{25}$

\footnotetext{
${ }^{24}$ For example, the facts that operators protest against termination rate reductions in CPP countries and that firms agree voluntary to Bill and Keep in RPP countries are consistent with our model predictions, while models employing responsive expectations are not.

${ }^{25}$ Hurkens and López (2012) calibrate welfare gains from regulation in the Spanish telecom market (assuming passive expectations), while Harbord and Hoernig (2012) do so for the UK (assuming responsive expectations). In both cases a CPP regime is assumed and results depend strongly on the strength of the call externality.
} 


\section{Appendix}

\section{Proof of Lemma 1.}

Suppose a network considers to raise the reception charge for off-net calls above $\beta \hat{p}^{*}$. Such a deviation would make the receivers of this network determine the volume of calls received from subscribers from rival networks. All firms $j \neq i$ set $\hat{p}_{j}=\hat{p}^{*}, \hat{r}_{j}=\hat{r}^{*}$, and $F_{j}=F^{*}$ where $\hat{p}^{*}$ and $\hat{r}^{*}$ satisfy (5) and $F^{*}$ satisfies (6) while firm $i$ sets $\hat{p}_{i}=\hat{p}^{*}, \hat{r}_{i}>\beta \hat{p}^{*}$, and $F_{i}$. The profit of firm $i$ is then equal to

$$
\pi_{i}=\alpha_{i}\left(\left(1-\alpha_{i}\right)\left(\hat{p}^{*}-c-m\right) q\left(\hat{p}^{*}\right)+\left(1-\alpha_{i}\right)\left(\hat{r}_{i}+m\right) q\left(\hat{r}_{i} / \beta\right)+F_{i}-f\right) .
$$

As before, when considering an alternative reception charge $\hat{r}_{i}$ one can keep market share constant at $1 / n$ by adjusting $F_{i}$ accordingly. That is,

$$
\begin{gathered}
F_{i}=\frac{n-1}{n}\left[\left(\beta u\left(q\left(\hat{r}_{i} / \beta\right)\right)-\hat{r}_{i} q\left(\hat{r}_{i} / \beta\right)\right)-\left(\beta u\left(q\left(\hat{p}^{*}\right)\right)-\hat{r}^{*} q\left(\hat{p}^{*}\right)\right)\right] \\
+\frac{1}{n}\left[\left(u\left(q\left(\hat{p}^{*}\right)-\hat{p}^{*} q\left(\hat{p}^{*}\right)\right)-\left(u\left(q\left(\hat{r}_{i} / \beta\right)\right)-\hat{p}^{*} q\left(\hat{r}_{i} / \beta\right)\right)\right]+F^{*}\right.
\end{gathered}
$$

Observe that

$$
\frac{\partial F_{i}}{\partial \hat{r}_{i}}=\frac{n-1}{n}\left[-q\left(\hat{r}_{i} / \beta\right)\right]-\frac{1}{n \beta^{2}}\left[\left(\hat{r}_{i}-\beta \hat{p}^{*}\right) q^{\prime}\left(\hat{r}_{i} / \beta\right)\right]
$$

Keeping market share $\alpha_{i}$ constant at $1 / n$, the first-order derivative of profit w.r.t. $\hat{r}_{i}$ is

$$
\begin{aligned}
\partial \pi_{i} / \partial \hat{r}_{i} & =\frac{1}{n}\left[\frac{n-1}{n}\left[q\left(\hat{r}_{i} / \beta\right)+\left(\hat{r}_{i}+m\right) q^{\prime}\left(\hat{r}_{i} / \beta\right) / \beta-q\left(\hat{r}_{i} / \beta\right)\right]-\frac{1}{n \beta^{2}}\left(\hat{r}_{i}-\beta \hat{p}^{*}\right) q^{\prime}\left(\hat{r}_{i} / \beta\right) / \beta\right] \\
& =\frac{q^{\prime}\left(\hat{r}_{i} / \beta\right)}{\beta^{2} n^{2}}\left[\beta(n-1)\left(\hat{r}_{i}+m\right)-\hat{r}_{i}+\beta \hat{p}^{*}\right] .
\end{aligned}
$$

Note that if $(n-1) \beta-1<0$, the profit function is U-shaped while if $(n-1) \beta-1>0$, the profit function is inversely $\mathrm{U}$-shaped. Moreover, at $\hat{r}_{i}=\beta \hat{p}^{*}$

$$
\frac{\partial \pi_{i}}{\partial \hat{r}_{i}}>0 \text { if and only if } \beta \hat{p}^{*}+m<0
$$

Hence, if $\beta \hat{p}^{*}+m<0$ firm $i$ will certainly want to deviate since even a marginal deviation above $\beta \hat{p}^{*}$ would be profitable. On the other hand, if $\beta \hat{p}^{*}+m>0$ marginal deviations are not profitable. If moreover, $(n-1) \beta-1>0$, then there is no profitable deviation at all, in which market shares are kept constant. By continuity there is no profitable deviation either in which market share is changed slightly. When $\mu$ is sufficiently high provoking larger 
market share deviations is very costly and cannot be profitable. Finally, if $\beta \hat{p}^{*}+m>0$ and $(n-1) \beta-1<0$ deviating to $\hat{r}_{i}=\infty$ may be profitable.

\section{Proof of Lemma 3.}

We will now check whether a firm $i$ may have an incentive to raise the off-net call price $\hat{p}_{i}$ above $\hat{r}^{*} / \beta$. Such a deviation makes the callers of this network determine the volume of off-net calls. Profit of firm $i$ is then equal to

$$
\pi_{i}=\alpha_{i}\left(\left(1-\alpha_{i}\right)\left(\hat{p}_{i}-c-m\right) q\left(\hat{p}_{i}\right)+\left(1-\alpha_{i}\right)\left(\hat{r}^{*}+m\right) q\left(\hat{r}^{*} / \beta\right)+F_{i}-f\right) .
$$

As before, when considering an alternative reception price, one can keep market share constant by adjusting $F_{i}$ accordingly. That is

$$
\begin{aligned}
F_{i} & =\frac{n-1}{n}\left[\left(u\left(q\left(\hat{p}_{i}\right)\right)-\hat{p}_{i} q\left(\hat{p}_{i}\right)\right)-\left(u\left(q\left(\hat{r}^{*} / \beta\right)\right)-\hat{p}^{*} q\left(\hat{r}^{*} / \beta\right)\right)\right] \\
& +\frac{1}{n}\left[\left(\beta u\left(q\left(\hat{r}^{*} / \beta\right)\right)-\hat{r}^{*} q\left(\hat{r}^{*} / \beta\right)\right)-\left(\beta u\left(q\left(\hat{p}_{i}\right)\right)-\hat{r}^{*} q\left(\hat{p}_{i}\right)\right)\right]+F^{*}
\end{aligned}
$$

Observe that

$$
\begin{gathered}
\frac{\partial F_{i}}{\partial \hat{p}_{i}}=\frac{n-1}{n}\left[-q\left(\hat{p}_{i}\right)\right]-\frac{1}{n}\left[\left(\beta \hat{p}_{i}-\hat{r}^{*}\right) q^{\prime}\left(\hat{p}_{i}\right)\right] . \\
0=\partial \pi_{i} / \partial \hat{p}_{i}=\alpha_{i}\left[\frac{n-1}{n}\left[q\left(\hat{p}_{i}\right)+\left(\hat{p}_{i}-c-m\right) q^{\prime}\left(\hat{p}_{i}\right)-q\left(\hat{p}_{i}\right)\right]-\frac{1}{n}\left(\beta \hat{p}_{i}-\hat{r}^{*}\right) q^{\prime}\left(\hat{p}_{i}\right)\right] \\
=\frac{q^{\prime}\left(\hat{p}_{i}\right)}{n^{2}}\left[(n-1-\beta) \hat{p}_{i}-(n-1)(c+m)+\hat{r}^{*}\right]
\end{gathered}
$$

so that

$$
(n-1-\beta) \hat{p}_{i}-(n-1)(c+m)+\hat{r}^{*}=0 .
$$

Note that the second-order derivative of profits, evaluated at the solution of the first-order condition, reads

$$
\frac{\partial^{2} \pi}{\partial \hat{p}_{i}^{2}}=\frac{q^{\prime}\left(\hat{p}_{i}\right)}{n^{2}}(n-1-\beta)<0
$$

for all $\beta<1$ and $n \geq 2$. A profitable (marginal) deviation above $\hat{r}^{*} / \beta$ thus exists whenever $\partial \pi / \partial \hat{p}_{i}>0$, when evaluated at $\hat{p}_{i}=\hat{r}^{*} / \beta$. So a necessary condition for the candidate equilibrium to be an equilibrium is that $\hat{r} \geq \beta(c+m)$. When $\mu$ is sufficiently high, it will then also not be profitable to deviate and change market share away from $1 / n$. For an equilibrium in which the receiver determines the call volume to exist it must be true that $\hat{r} \geq \beta(c+m)$ for $\hat{r}=\beta(n-1) m /[1-(n-1) \beta)]$ (that is for $\hat{p}=0)$. This implies the condition on $m$. 


\section{Proof of Proposition 9.}

Here we provide the details of equilibrium selection based on vanishing noise. It follows the approach by JLT (2004), who introduced this in a duopoly model assuming rationally responsive expectations. It turns out that neither the type of expectations nor the number of firms is relevant for which candidate equilibrium is selected. ${ }^{26}$

We assume that the utility that a receiver derives from receiving a call of length $q$ is subject to some noise $\varepsilon: \beta u(q)+\varepsilon q$, where $\varepsilon$ is distributed with cumulative distribution function $F(\cdot)$ on wide enough support $[\underline{\varepsilon}, \bar{\varepsilon}]$, zero mean, and strictly positive density function $f(\cdot)$. Additionally, $\varepsilon$ is identically and independently distributed for each caller-receiver pair. We will assume that noise vanishes in the following regular way (similar to JLT):

Definition 11 A sequence of distributions $F_{n}(\varepsilon)$ with zero mean on domain $[\underline{\varepsilon}, \bar{\varepsilon}]$ is called regular if for any continuous function $h(\cdot)$ we have

$$
\lim _{n \rightarrow \infty} E\left[h(\varepsilon) \mid \varepsilon \geq \varepsilon_{0}\right]=h\left(\varepsilon_{0}\right) \text { for all } \varepsilon_{0} \geq 0
$$

and

$$
\lim _{n \rightarrow \infty} E\left[h(\varepsilon) \mid \varepsilon \leq \varepsilon_{0}\right]=h\left(\varepsilon_{0}\right) \text { for all } \varepsilon_{0} \leq 0 .
$$

As receivers are allowed to hang up, for a given pair of relevant ${ }^{27}$ prices $\left(p_{i}, r_{j}\right)$ the length of a call from a caller of network $i$ to a receiver of network $j$ is given by $q\left(\max \left\{p_{i},\left(r_{j}-\varepsilon\right) / \beta\right\}\right)$. Therefore, the volume of calls from network $i$ to network $j$ is $\alpha_{i} \alpha_{j} D\left(p_{i}, r_{j}\right)$ with

$$
D\left(p_{i}, r_{j}\right)=\left[1-F\left(r_{j}-\beta p_{i}\right)\right] q\left(p_{i}\right)+\int_{\underline{\varepsilon}}^{r_{j}-\beta p_{i}} q\left(\frac{r_{j}-\varepsilon}{\beta}\right) f(\varepsilon) d \varepsilon .
$$

Observe that

$$
\frac{\partial D\left(p_{i}, r_{j}\right)}{\partial p_{i}}=\left[1-F\left(r_{j}-\beta p_{i}\right)\right] q^{\prime}\left(p_{i}\right),
$$

while

$$
\frac{\partial D\left(p_{i}, r_{j}\right)}{\partial r_{j}}=(1 / \beta) F\left(r_{j}-\beta p_{i}\right) E\left[q^{\prime}\left(\frac{r_{j}-\varepsilon}{\beta}\right) \mid \varepsilon \leq r_{j}-\beta p_{i}\right] .
$$

The utility that a consumer from network $i$ obtains from placing calls to network $j$ is $\alpha_{j} U\left(p_{i}, r_{j}\right)$ with

$$
U\left(p_{i}, r_{j}\right)=\left[1-F\left(r_{j}-\beta p_{i}\right)\right] u\left(q\left(p_{i}\right)\right)+\int_{\underline{\varepsilon}}^{r_{j}-\beta p_{i}} u\left(q\left(\frac{r_{j}-\varepsilon}{\beta}\right)\right) f(\varepsilon) d \varepsilon .
$$

\footnotetext{
${ }^{26}$ The number of firms is of course important to determine whether the candidate equilibrium is indeed an equilibrium, as shown before.

${ }^{27}$ With relevant prices we mean that if $i=j$, then we consider the on-net prices $p_{i}$ and $r_{i}$, while if $i \neq j$ we mean the off-net prices $\hat{p}_{i}$ and $\hat{r}_{j}$.
} 
Notice that

$$
\frac{\partial U\left(p_{i}, r_{j}\right)}{\partial p_{i}}=p_{i} \frac{\partial D\left(p_{i}, r_{j}\right)}{\partial p_{i}}
$$

while

$$
\frac{\partial U\left(p_{i}, r_{j}\right)}{\partial r_{j}}=(1 / \beta) F\left(r_{j}-\beta p_{i}\right) E\left[\frac{r_{j}-\varepsilon}{\beta} q^{\prime}\left(\frac{r_{j}-\varepsilon}{\beta}\right) \mid \varepsilon \leq r_{j}-\beta p_{i}\right] .
$$

The utility that a consumer from network $j$ obtains from receiving calls from network $i$ is $\alpha_{i} \widetilde{U}\left(p_{i}, r_{j}\right)$ with

$$
\begin{aligned}
\widetilde{U}\left(p_{i}, r_{j}\right)= & \int_{r_{j}-\beta p_{i}}^{\bar{\varepsilon}}\left[\beta u\left(q\left(p_{i}\right)\right)+\varepsilon q\left(p_{i}\right)\right] f(\varepsilon) d \varepsilon \\
& +\int_{\underline{\varepsilon}}^{r_{j}-\beta p_{i}}\left[\beta u\left(q\left(\frac{r_{j}-\varepsilon}{\beta}\right)\right)+\varepsilon q\left(\frac{r_{j}-\varepsilon}{\beta}\right)\right] f(\varepsilon) d \varepsilon .
\end{aligned}
$$

Notice that

$$
\frac{\partial \widetilde{U}\left(p_{i}, r_{j}\right)}{\partial r_{j}}=r_{j} \frac{\partial D\left(p_{i}, r_{j}\right)}{\partial r_{j}}
$$

while

$$
\frac{\partial \widetilde{U}\left(p_{i}, r_{j}\right)}{\partial p_{i}}=\left[1-F\left(r_{j}-\beta p_{i}\right)\right] E\left[\left(\beta p_{i}+\varepsilon\right) q^{\prime}\left(p_{i}\right) \mid \varepsilon \geq r_{j}-\beta p_{i}\right] .
$$

We will solve for the symmetric equilibrium (without connectivity breakdown). We start the analysis with the market for on-net calls. It is optimal for network $i$ to maximize the size of the pie for on-net calls. The first-order conditions with respect to $p_{i}$ reads

$$
\frac{\partial\left[U\left(p_{i}, r_{i}\right)+\tilde{U}\left(p_{i}, r_{i}\right)-c D\left(p_{i}, r_{i}\right)\right]}{\partial p_{i}}=0,
$$

while the one with respect to $r_{i}$ reads

$$
\frac{\partial\left[U\left(p_{i}, r_{i}\right)+\tilde{U}\left(p_{i}, r_{i}\right)-c D\left(p_{i}, r_{i}\right)\right]}{\partial r_{i}}=0 .
$$

Using the expressions for partial derivatives derived before, the system of equations is equivalent to

$$
\left\{\begin{array}{l}
0=E\left[\left(p_{i}-c+\beta p_{i}+\varepsilon\right) q^{\prime}\left(p_{i}\right) \mid \varepsilon \geq r_{i}-\beta p_{i}\right] \\
0=E\left[\left(r_{i}-c+\frac{r_{i}-\varepsilon}{\beta}\right) q^{\prime}\left(\frac{r_{i}-\varepsilon}{\beta}\right) \mid \varepsilon \leq r_{i}-\beta p_{i}\right]
\end{array}\right.
$$

Let $\left(p_{i}^{(n)}, r_{i}^{(n)}\right)$ denote the solution when the noise distribution is $F^{(n)}$. Without loss of generality we may assume that the sequence converges to $(p, r)$ and that $\beta p \geq r$ or that $\beta p \leq r$. If $r \leq \beta p$, then by the regularity of the sequence $F^{(n)}$ it must hold that 


$$
\left\{\begin{array}{l}
0=(p-c+\beta p) q^{\prime}(p) \\
0=(r-c+p) q^{\prime}(p)
\end{array}\right.
$$

so that $p=c /(1+\beta)$ and $r=\beta c /(1+\beta)$.

If $r \geq \beta p$, then by the regularity of the sequence $F^{(n)}$ it must hold that

$$
\left\{\begin{array}{l}
0=(p-c+r) q^{\prime}(p) \\
0=(r-c+r / \beta) q^{\prime}(r / \beta)
\end{array}\right.
$$

so that again $p=c /(1+\beta)$ and $r=\beta c /(1+\beta)$.

Hence, $p=p^{*}=c /(1+\beta)$ and $r=r^{*}=\beta c /(1+\beta)$.

We now solve for the optimal off-net call and reception charges. Let us fix the prices of all firms $j \neq i$ : $\left(p^{*}, r^{*}, \hat{p}, \hat{r}, F\right)$. Because consumers have passive expectations and we are considering symmetric equilibrium, all consumers expect market shares to be equal to $1 / n$. Expected surplus to subscribing to network $i$ is thus

$$
\begin{aligned}
w_{i}= & \frac{1}{n}\left(U\left(p^{*}, r^{*}\right)+\widetilde{U}\left(p^{*}, r^{*}\right)-c D\left(p^{*}, r^{*}\right)\right)-F_{i} \\
& +\frac{n-1}{n}\left(U\left(\hat{p}_{i}, \hat{r}\right)-\hat{p}_{i} D\left(\hat{p}_{i}, \hat{r}\right)+\widetilde{U}\left(\hat{p}, \hat{r}_{i}\right)-\hat{r}_{i} D\left(\hat{p}, \hat{r}_{i}\right)\right),
\end{aligned}
$$

while subscribing to any of the rival networks $j$ yields surplus

$$
\begin{aligned}
w_{j}= & \frac{1}{n}\left(U\left(p^{*}, r^{*}\right)+\widetilde{U}\left(p^{*}, r^{*}\right)-c D\left(p^{*}, r^{*}\right)\right)-F \\
& +\frac{1}{n}\left(U\left(\hat{p}, \hat{r}_{i}\right)-\hat{p} D\left(\hat{p}, \hat{r}_{i}\right)+\widetilde{U}\left(\hat{p}_{i}, \hat{r}\right)-\hat{r} D\left(\hat{p}_{i}, \hat{r}\right)\right) \\
& +\frac{n-2}{n}(U(\hat{p}, \hat{r})-\hat{p} D(\hat{p}, \hat{r})+\widetilde{U}(\hat{p}, \hat{r})-\hat{r} D(\hat{p}, \hat{r})) .
\end{aligned}
$$

The surplus in the first line corresponds to on-net calls and fixed fee, the surplus in the second line to off-net calls from and to network $i$, and the surplus in the last line corresponds to off-net traffic from and to other networks.

In order to keep true market share constant when changing $\hat{p}_{i}$ and $\hat{r}_{i}$, network $i$ should adjust fixed fee so that $w_{i}-w_{j}$ remains constant, so that 


$$
\begin{aligned}
& \frac{\partial F_{i}}{\partial \hat{p}_{i}}=-\frac{n-1}{n} D\left(\hat{p}_{i}, \hat{r}\right)-\frac{1}{n}\left(\frac{\partial \widetilde{U}\left(\hat{p}_{i}, \hat{r}\right)}{\partial \hat{p}_{i}}-\hat{r} \frac{\partial D\left(\hat{p}_{i}, \hat{r}\right)}{\partial \hat{p}_{i}}\right) \\
& \frac{\partial F_{i}}{\partial \hat{r}_{i}}=-\frac{n-1}{n} D\left(\hat{p}, \hat{r}_{i}\right)-\frac{1}{n}\left(\frac{\partial U\left(\hat{p}, \hat{r}_{i}\right)}{\partial \hat{r}_{i}}-\hat{p} \frac{\partial D\left(\hat{p}, \hat{r}_{i}\right)}{\partial \hat{r}_{i}}\right) .
\end{aligned}
$$

Observe that no profit is made on on-net traffic so that

$$
\pi_{i}=\alpha_{i}\left(F_{i}+\left(1-\alpha_{i}\right)\left[\left(\hat{p}_{i}-(c+m)\right) D\left(\hat{p}_{i} \hat{r}\right)+\left(\hat{r}_{i}+m\right) D\left(\hat{p}, \hat{r}_{i}\right)\right]\right) .
$$

Maximizing profit while holding market share constant through adjusting fixed fee $F_{i}$ thus yields

$$
\left\{\begin{array}{l}
0=\frac{\partial \pi_{i}}{\partial \hat{p}_{i}}=\alpha_{i}\left(\frac{\partial F_{i}}{\partial \hat{p}_{i}}+\left(1-\alpha_{i}\right)\left[D\left(\hat{p}_{i}, \hat{r}\right)+\left(\hat{p}_{i}-(c+m)\right) \frac{D\left(\hat{p}_{i}, \hat{r}\right)}{\partial \hat{p}_{i}}\right]\right) \\
0=\frac{\partial \pi_{i}}{\partial \hat{r}_{i}}=\alpha_{i}\left(\frac{\partial F_{i}}{\partial \hat{r}_{i}}+\left(1-\alpha_{i}\right)\left[D\left(\hat{p}, \hat{r}_{i}\right)+\left(\hat{r}_{i}+m\right) \frac{D\left(\hat{p}, \hat{r}_{i}\right)}{\partial \hat{r}_{i}}\right]\right)
\end{array}\right.
$$

Using that at a symmetric equilibrium $\alpha_{i}=1 / n$ these equations can be rewritten as

$$
\left\{\begin{array}{l}
0=-\frac{\partial \widetilde{U}\left(\hat{p}_{i}, \hat{r}\right)}{\partial \hat{p}_{i}}+\hat{r} \frac{\partial D\left(\hat{p}_{i}, \hat{r}\right)}{\partial \hat{p}_{i}}+(n-1)\left(\hat{p}_{i}-(c+m)\right) \frac{D\left(\hat{p}_{i}, \hat{r}\right)}{\partial \hat{p}_{i}} \\
0=-\frac{\left.\partial U \hat{p}, \hat{r}_{i}\right)}{\partial \hat{r}_{i}}+\hat{p} \frac{\partial D\left(\hat{p}, \hat{r}_{i}\right)}{\partial \hat{r}_{i}}+(n-1)\left(\hat{r}_{i}+m\right) \frac{D\left(\hat{p}, \hat{r}_{i}\right)}{\partial \hat{r}_{i}}
\end{array}\right.
$$

Substituting Eqs. (13), (14), (16) and (18) and taking out non-negative factors $[1-F(\hat{r}-$ $\left.\left.\beta \hat{p}_{i}\right)\right]$ and $F\left(\hat{r}_{i}-\beta \hat{p}\right) / \beta$, this can be rewritten as

$$
\left\{\begin{array}{l}
0=E\left[-\beta \hat{p}_{i}-\varepsilon+\hat{r}+(n-1)\left(\hat{p}_{i}-(c+m)\right) \mid \varepsilon \geq \hat{r}-\beta \hat{p}_{i}\right] q^{\prime}\left(\hat{p}_{i}\right) \\
0=E\left[\left(-\frac{\hat{r}_{i}-\varepsilon}{\beta}+\hat{p}+(n-1)\left(\hat{r}_{i}+m\right)\right) q^{\prime}\left(\frac{\hat{r}_{i}-\varepsilon}{\beta}\right) \mid \varepsilon \leq \hat{r}_{i}-\beta \hat{p}\right]
\end{array}\right.
$$

Let $F^{(n)}$ represent a series of noise distributions that is regular and let $\left(\hat{p}^{(n)}, \hat{r}^{(n)}\right)$ denote the corresponding symmetric equilibrium candidate usage prices. By taking a suitable subsequence one may assume that either $\hat{r}^{n}-\beta \hat{p}^{n} \leq 0$ for all $n$ or that $\hat{r}^{n}-\beta \hat{p}^{n} \geq 0$ for all $n$.

Consider the first case. Then in the limit, as noise vanishes, the limit point $(\hat{p}, \hat{r})$ must satisfy $\hat{r}-\beta \hat{p} \leq 0$ and

$$
\begin{aligned}
& 0=[(n-1-\beta) \hat{p}-(n-1)(c+m)+\hat{r}] q^{\prime}\left(\hat{p}_{i}\right) \\
& 0=(n-1)(\hat{r}+m) q^{\prime}(\hat{p})
\end{aligned}
$$

so that (if $m \leq 0) \hat{r}=-m$ and $\hat{p}=((n-1) c+n m) /(n-1-\beta)$. The condition $\hat{r}-\beta \hat{p} \leq 0$ 
is satisfied if and only if $m \geq \bar{m}$.

Consider the second case next. Then in the limit, as noise vanishes, the limit point $(\hat{p}, \hat{r})$ must satisfy $\hat{r}-\beta \hat{p} \geq 0$ and

$$
\begin{aligned}
& 0=(n-1)(\hat{p}-(c+m)) \\
& 0=(\hat{r}(n-1-1 / \beta)+\hat{p}+(n-1) m) q^{\prime}(\hat{r} / \beta)
\end{aligned}
$$

so that $\hat{p}=c+m$ and $\hat{r}=-\beta(c+n m) /((n-1) \beta-1)$. The condition $\hat{r}-\beta \hat{p} \geq 0$ is satisfied if and only if $m \leq \bar{m}$.

\section{Proof of Proposition 10.}

[i] The result on call and reception charges follows exactly the analysis under passive expectations. With noise both first-order conditions w.r.t. call and reception charges (while keeping market share constant by adjusting the fixed fee) are necessary. The limiting case of vanishing noise yields thus exactly the same variable prices as under passive expectations in Proposition 9. In order to determine the fixed fee, we need to take into account that market shares respond differently to changes in fixed fees under responsive expectations. In order to emphasize the fact that we are now assuming responsive expectations, we will use $\widetilde{\alpha}_{i}$ to denote market share. Profit of firm $i$ is, as before,

$$
\widetilde{\pi}_{i}=\widetilde{\alpha}_{i}\left(F_{i}-f+\left(1-\widetilde{\alpha}_{i}\right)(\hat{p}+\hat{r}-c) D(\hat{p}, \hat{r})\right) .
$$

Under responsive expectations the change in market share after a change in fixed fee is different: $\partial \widetilde{\alpha_{i}} / \partial F_{i} \neq \partial \alpha_{i} / \partial F_{i}$. Subscribing to network $j$ yields surplus

$$
w_{j}=\widetilde{\alpha}_{j} v^{*}+\left(1-\widetilde{\alpha_{j}}\right) \hat{v}-F_{j} .
$$

Hence, for $j \neq i$

$$
\frac{\partial w_{j}}{\partial F_{i}}=\frac{\partial \widetilde{\alpha_{j}}}{\partial F_{i}}\left(v^{*}-\hat{v}\right)
$$

and

$$
\frac{\partial w_{i}}{\partial F_{i}}=\frac{\partial \widetilde{\alpha_{i}}}{\partial F_{i}}\left(v^{*}-\hat{v}\right)-1 .
$$

Note that

$$
\frac{\partial \widetilde{\alpha_{j}}}{\partial F_{i}}=-\frac{1}{n-1} \frac{\partial \widetilde{\alpha_{i}}}{\partial F_{i}} .
$$

Using

$$
\frac{\partial \widetilde{\alpha_{i}}}{\partial F_{i}}=\frac{\widetilde{\alpha}_{i}\left(1-\widetilde{\alpha}_{i}\right)}{\mu}\left(\frac{\partial w_{i}}{\partial F_{i}}-\frac{\partial w_{j}}{\partial F_{i}}\right)
$$


we obtain

$$
\frac{\partial \widetilde{\alpha_{i}}}{\partial F_{i}}=\frac{-\widetilde{\alpha_{i}}\left(1-\widetilde{\alpha_{i}}\right)}{\mu-\widetilde{\alpha_{i}}\left(1-\widetilde{\alpha_{i}}\right)\left(v^{*}-\hat{v}\right)(n /(n-1))} .
$$

At the symmetric equilibrium $\widetilde{\alpha_{i}}=1 / n$ so that

$$
\frac{\partial \widetilde{\alpha_{i}}}{\partial F_{i}}=\frac{-(n-1)}{\mu n^{2}-n\left(v^{*}-\hat{v}\right)} .
$$

From the first-order condition $0=\partial \widetilde{\pi} / \partial F_{i}$ we obtain

$$
\tilde{F}=\frac{-1 / n}{\partial \widetilde{\alpha_{i}} / \partial F_{i}}+f-\frac{n-2}{n}(\hat{p}+\hat{r}-c) D(\hat{p}, \hat{r})
$$

Hence,

$$
\tilde{F}=f+\frac{n \mu}{n-1}-\frac{v^{*}-\hat{v}}{n-1}-\frac{n-2}{n}(\hat{p}+\hat{r}-c) D(\hat{p}, \hat{r})
$$

and

$$
\tilde{\pi}^{*}=\frac{\mu}{n-1}-\frac{v^{*}-\hat{v}}{n(n-1)}+\frac{1}{n^{2}}(\hat{p}+\hat{r}-c) D(\hat{p}, \hat{r})
$$

Substituting the equilibrium off-net call and reception charges yields

$$
\begin{aligned}
n^{2} \frac{\partial \widetilde{\pi}}{\partial m}= & \frac{n}{n-1} \frac{\partial \hat{v}}{\partial m}+\frac{\partial}{\partial m}[(\hat{p}+\hat{r}-c) D(\hat{p}, \hat{r})] \\
= & \frac{n}{n-1}\left[(1+\beta) u^{\prime} \frac{\partial D}{\partial m}-\frac{\partial(\hat{p}+\hat{r})}{\partial m} D-(\hat{p}+\hat{r}) \frac{\partial D}{\partial m}\right] \\
& +\frac{\partial(\hat{p}+\hat{r})}{\partial m} D+(\hat{p}+\hat{r}-c) \frac{\partial D}{\partial m}
\end{aligned}
$$

Note that at $m=\bar{m}, \hat{p}=\hat{r} / \beta=c /(1+\beta)$, so that $\hat{p}+\hat{r}=c$ and $u^{\prime}=c /(1+\beta)$ (both when taking the derivative from the right and from the left). Hence,

$$
\left.n^{2} \frac{\partial \widetilde{\pi}}{\partial m}\right|_{m=\bar{m}}=\frac{-D}{n-1} \frac{\partial[\hat{p}+\hat{r}]}{\partial m}
$$

which is negative (positive) when taking derivative from the right (left), as $\hat{p}+\hat{r}$ obtains the minimum at $m=\bar{m}$. This proves that a (local) maximum is obtained at $\bar{m}$. 


\section{References}

Anderson, S.P. and de Palma, A. (1992). 'The Logit as a model of product differentiation', Oxford Economic Papers, vol. 44(1), pp. 51-67.

Anderson, S.P., de Palma, A. and Thisse, J.-F. (1992). Discrete Choice Theory of Product Differentiation, The MIT Press, Cambridge (MA).

Armstrong, M., 1998. Network interconnection in telecommunications. The Economic Journal 108, 545-564.

Armstrong, M., 2002. The theory of access pricing and interconnection. In: Cave, M.E., Majumdar, S.K., Vogelsang, I. (Eds.), Handbook of Telecommunications Economics. NorthHolland, Amsterdam.

Armstrong, M. and Wright, J., 2009. Mobile call termination. The Economic Journal 119, F270-F307.

Berger, U., 2004. Access charges in the presence of call externalities. Contributions to Economic Analysis \& Policy 3: Iss. 1, Article 21.

Berger, U., 2005. Bill-and-Keep vs. cost-based access pricing revisited. Economics Letters $86,107-112$.

de Bijl, P., van Damme, E., Brunekreeft, G., Larouche, P., Sorana, V. and Shelkoplyas, N., 2005. Interconnected Networks. TILEC Discussion Paper Series 2005-007. Available at SSRN: http://ssrn.com/abstract=871391.

Calzada, J. and Valletti, T.M., 2008. Network competition and entry deterrence. The Economic Journal 118, 1223-1244.

Cambini, C. and Valletti, T.M., 2008. Information exchange and competition in communications networks. The Journal of Industrial Economics 56, 707-728.

DeGraba, P., 2003. Efficient intercarrier compensation for competing networks when customers share the value of a call. Journal of Economics \& Management Strategy 12, 207-230.

Dessein, W., 2003. Network competition in nonlinear pricing. RAND Journal of Economics 34, 593-611.

Dessein, W., 2004. Network competition with heterogenous customers and calling patterns. Information Economics and Policy 16, 323-345. 
Dewenter, R. and Kruse, J., 2011. Calling party pays or receiving party pays? The diffusion of mobile telephony with endogenous regulation. Information Economics and Policy 23, 107117 .

Gans, J.S. and King, S.P., 2001. Using 'Bill and Keep' interconnect arrangements to soften network competition. Economics Letters 71, 413-420.

Hahn, J-H, 2003. Nonlinear pricing of telecommunications with call and network externalities. International Journal of Industrial Organization 21, 949-967.

Harbord, D. and Hoernig, S., 2012. Welfare analysis of regulating mobile termination rates in the UK with an application to the Orange T-Mobile Merger. Nova SBE WP 571.

Hermalin, B. and Katz, M.L., 2001. Network interconnection with two-sided user benefits. Mimeo, University of California-Berkeley.

Hermalin, B. and Katz, M.L., 2004. Sender or receiver: who should pay to exchange an electronic message?. RAND Journal of Economics 35, 423-448.

Hermalin, B. and Katz, M.L., 2011. Customer or Complementor? Intercarrier Compensation with Two-Sided Benefits. Journal of Economics \& Management Strategy 20, 379-408.

Hoernig, S., 2012. The breakdown of connectivity breakdowns. CEPR DP 9189.

Hoernig, S., Inderst, R. and Valletti, T., 2014. Calling circles: Network competition with nonuniform calling patterns. RAND Journal of Economics, 45, 155-175. doi: 10.1111/17562171.12046

Hurkens, S. and Jeon, D.S. 2012. 'Promoting network competition by regulating termination charges', International Journal of Industrial Organization, vol. 30(6), pp. 541-52.

Hurkens, S. and López, Á.L., 2012. The welfare effects of mobile termination rate regulation in asymmetric oligopolies: The case of Spain. telecommunications Policy, 36, 369-381.

Hurkens, S. and López, Á.L., 2014. Mobile termination, network externalities, and consumer expectations. The Economic Journal, doi: 10.1111/ecoj.12097.

Jeon, D.S., Laffont, J.-J. and Tirole, J., 2004. On the receiver pays principle. RAND Journal of Economics 35, 85-110.

Jullien, B., Rey, P. and Sand-Zantman, W. 2013. 'Termination fees revisited', International Journal of Industrial Organization 31, 738-750. 
Kim, J.-Y. and Lim. Y., 2001. An economic analysis of the receiver pays principle. Information Economics and Policy 13, 231-260.

Laffont, J.-J., Rey, P. and Tirole, J., 1998a. Network competition: I. Overview and nondiscriminatory pricing. RAND Journal of Economics 29, 1-37.

Laffont, J.-J., Rey, P. and Tirole, J., 1998b. Network competition: II. Price discrimination. RAND Journal of Economics 29, 38-56.

Laffont, J.-J., Marcus, S., Rey, P. and Tirole, J., 2003. Internet interconnection and the off-net-cost pricing principle. RAND Journal of Economics 34, 370-390.

Littlechild, S.C., 2006. Mobile termination charges: Calling Party Pays versus Receiving Party Pays. Telecommunications Policy 30, 242-277.

López, Á.L., 2011. Mobile termination rates and the receiver-pays regime. Information Economics and Policy 23, 171-181.

López, Á.L., and Rey, P. 2012. 'Foreclosing competition through access charges and price discrimination', Working Paper, Institut d'Economie Industrielle.

Peitz, M., Valletti, T.M. and Wright, J., 2004. Competition in telecommunications: an introduction. Information Economics and Policy 16, 315-321.

Small, K.A., and Rosen, H.S. (1981). 'Applied welfare economics with discrete choice models', Econometrica, vol. 49(1), pp. 105-30.

Valletti, T.M. and Houpis, G. 2005. Mobile termination: What is the right charge?', Journalof Regulatory Economics, 28, 235-258.

Vogelsang, I., 2003. Price regulation of access to telecommunications networks. Journal of Economic Literature 41, 830-862. 